\begin{tabular}{|c|l|}
\hline Title & $\begin{array}{l}\text { Oceanic Rossby Waves over Eastern Tropical Pacific of Both Hemispheres Forced by A nomal ous Surface Winds after } \\
\text { Mature Phase of ENSO }\end{array}$ \\
\hline Author(s) & A be, Hiroto; Tanimoto, Y ouichi; Hasegawa, Takuya; Ebuchi, Naoto \\
\hline Citation & $\begin{array}{l}\text { Journal of Physical Oceanography, 46(11), 3397-3414 } \\
\text { https://doi.org/10.1175/PO-D-15-0118.1 }\end{array}$ \\
\hline Issue Date & 2016-11-10 \\
\hline Doc URL & http://hdl.handle.net/2115/65231 \\
\hline Rights & ○ Copyright 2016-11-10 AMS \\
\hline Type & article \\
\hline File Information & JPO-D-15-0118.1.pdf \\
\hline
\end{tabular}

Instructions for use 


\title{
¿ Oceanic Rossby Waves over Eastern Tropical Pacific of Both Hemispheres Forced by Anomalous Surface Winds after Mature Phase of ENSO
}

\author{
Hiroto $\mathrm{ABE}^{\mathrm{a}}$ \\ Institute of Low Temperature Science, Hokkaido University, Sapporo, Hokkaido, Japan \\ YOUICHI TANIMOTO \\ Faculty of Environmental Earth Science, Hokkaido University, Sapporo, Hokkaido, and Application Laboratory, \\ Japan Agency for Marine-Earth Science and Technology, Yokohama, Kanagawa, Japan \\ TAKUYA HASEGAWA \\ Research and Development Center for Global Change, Japan Agency for Marine-Earth Science \\ and Technology, Yokosuka, Kanagawa, Japan \\ NAOTO EBUCHI \\ Institute of Low Temperature Science, Hokkaido University, Sapporo, Hokkaido, Japan
}

(Manuscript received 15 June 2015, in final form 25 August 2016)

\begin{abstract}
The present study examined ENSO-related wind forcing contribution to off-equatorial Rossby wave formations in the eastern tropical regions of the North and South Pacific using satellite altimeter data and atmospheric reanalysis data during the period of 1993-2013. After mature phases of ENSO events, the sea surface height anomaly fields showed that off-equatorial Rossby waves propagated westward along $11^{\circ} \mathrm{N}$ and $8^{\circ} \mathrm{S}$ from the eastern Pacific. Starting longitudes of the westward propagation were distant from the eastern coast, especially for weak El Niño events in the 2000s, in contrast to the strong 1997/98 El Niño event in which the propagations started from the coast. Based on observational data, it was hypothesized that the Rossby waves could be formed by off-equatorial zonal belts of wind stress curl anomalies (WSCAs) in $135^{\circ}-90^{\circ} \mathrm{W}$ rather than by wave emissions from the eastern coast. A numerical model forced only by WSCAs, that is, without wave emissions from the coast, successfully reproduced observed features of the Rossby waves in $180^{\circ}-120^{\circ} \mathrm{W}$, supporting the study's hypothesis. During mature phases of El Niño events, equatorially symmetric negative sea level pressure anomalies (SLPAs) resulting from hydrostatic adjustment to the underlying warm sea surface temperature anomalies dominated over the eastern tropical Pacific. Anomalous surface easterlies blowing around the negative SLPA area as geostrophic winds were a major contributor in forming the anticyclonic WSCAs. The polarity of the anomalies is reversed during La Niña events. Therefore, spatial patterns of the SLPAs associated with the ENSO events are necessary to understand the Rossby wave formations.
\end{abstract}

๑ Denotes Open Access content.

\footnotetext{
${ }^{a}$ Current affiliation: Atmosphere and Ocean Research Institute, University of Tokyo, Kashiwa, Chiba, Japan.
}

Corresponding author address: Dr. Hiroto Abe, Atmosphere and Ocean Research Institute, University of Tokyo, 5-1-5, Kashiwanoha, Kashiwa-shi, Chiba 277-8564, Japan.

E-mail: abeh@aori.u-tokyo.ac.jp

\section{Introduction}

In association with a cycle of the El Niño-Southern Oscillation (ENSO), the variations in the thermocline depth in the eastern tropical Pacific show propagation features as oceanic Rossby waves (Kessler 1990; Hasegawa and Hanawa 2003; White et al. 2003). After the mature phase of the ENSO warm event (El Niño) that is induced by arrival of the downwelling equatorial Kelvin wave, downwelling Rossby waves begin to propagate 
along latitude bands of $10^{\circ}-20^{\circ} \mathrm{N}$ and $10^{\circ}-20^{\circ} \mathrm{S}$. The appearances of these two downwelling Rossby waves on each side of the equator are mostly simultaneous, while the wave propagation features are different. The Rossby wave observed in the North Pacific propagates from the eastern coast to the western coast within $1 \mathrm{yr}$ and then reflects on the western coastal boundary to become downwelling Kelvin wave at the equator that finally induces subsequent El Niño (Kessler 1990; White et al. 2003; Hasegawa and Hanawa 2003, 2007), whereas the Rossby wave observed in the South Pacific decays as it propagates westward owing to modulation by atmospheric forcing in the central/western tropical Pacific (Hasegawa et al. 2008) and dissipation and vertical propagation of wave energy (Ramos et al. 2008). The polarity of the off-equatorial Rossby waves is reversed during the ENSO cold event (La Niña).

In many previous studies, these Rossby wave formations have been considered a result of the boundary effect of the equatorial and coastal Kelvin waves. After the equatorial Kelvin wave impinges on the eastern coastal boundary, the downwelling equatorial Kelvin wave bifurcates to the north and south and then further propagates poleward as a coastal Kelvin wave to high latitudes along the North American (Strub and James 2002; Clarke and Van Gorder 1994) and South American coasts (Blanco et al. 2002; Pizarro et al. 2002). They emit part of their wave energies off the coast in the midst of the poleward propagations (McWilliams 2006; Giunipero and Clarke 2013). It is because the coastal Kelvin wave, whose offshore scale is the Rossby's deformation radius, decreases with poleward propagation, which forces the coastal Kelvin wave to adjust to its changing environment (McWilliams 2006). Another study indicates that whether a wave is trapped or not depends on its frequency and vertical structure (Clarke and Shi 1991). The emitted ocean waves eventually propagate westward as downwelling Rossby waves into the interior regions of the North Pacific (Fu and Qiu 2002) and South Pacific (Vega et al. 2003; Ramos et al. 2008). These boundary-driven Rossby waves are clearly observed for the 1997/98 El Niño event while the similar boundary effect for the other ENSO events has not been reported by the previous studies.

Recently, Abe et al. (2014) suggested that this downwelling Rossby wave in the North Pacific could be generated by winds rather than the Kelvin wave reflection for most of the El Niño events. They pointed out that an anticyclonic WSCA was formed in $9^{\circ}-15^{\circ} \mathrm{N}$ as a result of southward shift of the intertropical convergence zone (ITCZ) during the mature phase of El Niño, explaining the downwelling Rossby wave formation. During the mature phase of La Niña, a cyclonic WSCA associated with northward shift of the ITCZ generates the upwelling Rossby wave. This latitude band of the Rossby wave's propagation path agrees well with the local maximum of wind-induced North Pacific thermocline depth variability and hence sea surface height variability at $13^{\circ} \mathrm{N}$ (Capotondi et al. 2003). Also, the appearance of the anticyclonic WSCA for the downwelling Rossby wave formation (the cyclonic WSCA for the upwelling Rossby wave formation) in $9^{\circ}-15^{\circ} \mathrm{N}$ is consistent with the fact that wind-induced sea surface height ( $\mathrm{SSH})$ variability is dominant in the eastern tropical North Pacific except for the 1997/98 El Niño event (Fu and Qiu 2002).

However, the formation process of the downwelling Rossby waves in the eastern tropical South Pacific is not clear. While the downwelling Rossby wave in the eastern tropical North Pacific could be explained by the southward shift of the ITCZ, there is not such atmospheric structure in the eastern tropical South Pacific. In addition, recent satellite observation revealed the frequent occurrence of weak El Niño events in the 2000s after the strong 1997/98 El Niño event (Larkin and Harrison 2005; Ashok et al. 2007; Yu and Kao 2007; Kug et al. 2009; Singh et al. 2011), which enables us to compare offequatorial ocean responses to strong/weak El Niño. The questions raised in the present study are 1) whether the ENSO-related Rossby waves in the eastern tropical South Pacific are wind driven or not, 2) what is the difference in the ENSO-related Rossby waves between strong and weak El Niño events, and 3) if these Rossby waves are wind driven like those in the eastern tropical North Pacific, what pattern in the ENSO-related atmosphere is explainable for the interbasin Rossby wave formations? We treat the ENSO-related Rossby waves in both the eastern tropical North and South Pacific together, aiming at providing comprehensive understanding on the interbasin Rossby wave formations.

The ENSO-related Rossby waves in the present study are different from those in Schopf and Suarez's (1988) conceptual ENSO model, known as the delayed-action oscillator model, in respect to the polarity and propagating latitudes. Schopf and Suarez (1988) discussed the Rossby waves found in the near-equatorial regions at $5^{\circ}$ $7^{\circ} \mathrm{N}$ and $5^{\circ}-7^{\circ} \mathrm{S}$, with the opposite polarity of the equatorial Kelvin wave. An issue as to whether the Rossby waves are wind driven or not has a close relation to the topic of Picaut et al.'s (1997) conceptual ENSO model, so-called the advective-reflective oscillator model, whose model is constructed based on an assumption of Kelvin wave reflection at the eastern coastal boundary.

An understanding of the linkage of the equatorial Kelvin wave and off-equatorial Rossby waves in the eastern tropical Pacific would contribute to a better 
forecast of off-equatorial SSH and ocean current variabilities in the entire tropical Pacific. In addition, the $\mathrm{SSH}$ variability is a critical issue for those who live on Pacific islands of low elevation above sea level that are at risk of going under water in the background of sea level rise associated with global warming.

In the present study, we attempt to show that the ENSO-related wind forcing, rather than the Kelvin wave reflection, can excite the ENSO-related, oceanic Rossby waves in the off-equatorial region $\left(5^{\circ}-20^{\circ} \mathrm{S}\right.$ and $\left.5^{\circ}-20^{\circ} \mathrm{N}\right)$ of the eastern tropical Pacific. The paper is organized as follows: Section 2 describes the data and methods, section 3 presents results of the present study, section 4 discusses the results in comparison with those of other relevant works, and section 5 presents a summary.

\section{Data and methods}

To examine contribution of the ENSO-related wind forcing to Rossby wave formations in the eastern tropical North and South Pacific, sea surface height anomaly (SSHA), sea surface temperature (SST), sea level pressure (SLP), and wind stress data have been used in the analysis. These data will be explained in section $2 \mathrm{a}$. In addition, analysis methods and a simple dynamic model will be explained in sections $2 \mathrm{~b}$ and $2 \mathrm{c}$, respectively.

\section{a. Data}

Datasets used in the present study are the same as those of Abe et al. (2014). For this reason, the description of the dataset parallels that of Abe et al. (2014) in this subsection.

SSHAs observed by satellite altimeters including TOPEX/Poseidon, Jason-1, and Jason-2 are provided by the Archiving, Validation, and Interpretation of Satellite Oceanographic data (AVISO). While the original anomaly data along the ground tracks of these satellites are available at 9.916-day and 5.8-km intervals, monthly averages that were smoothed by a Gaussian filter with an $e$-folding scale of $300 \mathrm{~km}$ were calculated.

SST data were provided by the Met Office Hadley Centre (HadISST; Rayner et al. 2003). The HadISST data are constructed based on quality-controlled in situ temperature observations and are available at 1-month intervals with a grid of $1^{\circ}$ longitude $\times 1^{\circ}$ latitude. Spatial and temporal gaps are filled using reduced-space optimal interpolation (Kaplan et al. 1997).

Surface wind velocity, surface wind stress, and SLP data provided by the European Center for MediumRange Weather Forecasts (ECMWF), referred to as the ECMWF interim reanalysis (ERA-Interim; Simmons et al. 2010), were used. The number of assimilated observations is 10 times larger in the ERA-Interim dataset than in the previous version of the 40-yr ECMWF ReAnalysis (ERA-40; Dee et al. 2011). Although the original data are available at 1-month intervals and with a grid of $0.75^{\circ}$ longitude $\times 0.75^{\circ}$ latitude, the data were regridded onto $1^{\circ}$ grids.

The data used in the present study were obtained between January 1993 and December 2013. Monthly climatologies were calculated over the 21-yr period for all atmospheric and oceanic variables. Monthly anomalies as departures from the respective climatologies were smoothed by applying a 13-month running-mean filter. This temporal filter highlighted the interannual variations in these variables by canceling out temporal variations on a 1-yr scale.

To represent the ENSO cycle in the equatorial eastern Pacific from 1993 to 2013, the Niño-3.4 index provided by the NOAA Climate Prediction Center was used.

\section{b. Analysis methods}

To extract the ENSO-related atmospheric and oceanic components, we used a regression analysis by relating these variables to the Niño-3.4 index. Statistical significance of the regression coefficients was evaluated based on correlation coefficient between each variable and Niño-3.4 index. The degree of freedom (DOF) was calculated by dividing the number of data by the zero-crossing time scale. The DOF of each variable and that of Niño-3.4 index were averaged to determine single value of DOF.

To estimate the propagation speed of the SSHAs, we followed the method of Abe et al. (2014). In a longitudetime diagram of the SSHAs, the SSHAs were projected onto a line at a given angle of $\theta$ to calculate along-slope SSHA variance. Along-slope SSHA variance is variance of SSHA anomaly that is defined by SSHA minus mean SSHA averaged over the line of angle $\theta$. Total variance of the along-slope SSHA is calculated by summing the along-slope SSHA variances over all lines of angle $\theta$. The $\theta$ ranges from $0^{\circ}$ (the longitude axis) to $90^{\circ}$ (the time axis). This variance would be minimized when the line is parallel to the alignment of ridges and troughs of the SSHAs. The optical $\theta$ in this diagram was converted to propagation speed.

\section{c. A 1.5-layer reduced-gravity model}

A linear vorticity model used in the present study is the same as that of Abe et al. (2014). For this reason, the model description is the same as Abe et al. (2014), and the following text is derived from there with minor modifications.

To estimate wind-induced SSHAs, a 1.5-layer baroclinic Rossby wave model was employed, which has successfully reproduced Rossby wave features in many previous studies (e.g., Meyers 1979; Kessler 1990; Holbrook and Bindoff 1999; Perkins and Holbrook 
2001; Cummins and Lagerloef 2004; Fu and Qiu 2002; Capotondi et al. 2003; Qiu and Chen 2010; Abe et al. 2014). Under the long-wave approximation, a linear vorticity equation is obtained:

$$
\frac{\partial h^{\prime}}{\partial t}-C_{R} \frac{\partial h^{\prime}}{\partial x}=-\frac{g^{\prime}}{\rho_{0} g} \mathbf{k} \cdot \nabla \times\left(\tau^{\prime} / f\right)-\varepsilon h^{\prime},
$$

where $h^{\prime}$ is the SSHA, $\tau^{\prime}$ is the wind stress anomaly vector, $C_{R}$ is the propagation speed of the long baroclinic Rossby waves, $g^{\prime}$ is the reduced gravity, $\rho_{0}$ is the reference density, $f$ is the Coriolis parameter, $\mathbf{k}$ is a unit vector normal to the $x-y$ plane, and $\varepsilon$ is the dissipation ratio. This long-wave approximation is supported by Fu and Qiu (2002), Kessler (1990), Perkins and Holbrook (2001), and Capotondi et al. (2003), who used the 1.5-layer or 2-layer models in the same region. Integrating Eq. (1) from the eastern boundary $x_{E}$ along the baroclinic Rossby wave characteristic gives

$$
\begin{aligned}
h^{\prime}(x, y, t)= & h^{\prime}\left(x_{E}, y, t+\frac{x-x_{E}}{C_{R}}\right) \exp \left[\varepsilon\left(x-x_{E}\right) / C_{R}\right] \\
& +\frac{g^{\prime}}{\rho_{0} g C_{R}} \int_{x_{E}}^{x} \mathbf{k} \cdot \nabla \times\left[\tau^{\prime}\left(x^{\prime}, y, t+\frac{x-x^{\prime}}{C_{R}}\right) / f\right] \exp \left[\varepsilon\left(x-x^{\prime}\right) / C_{R}\right] d x^{\prime} .
\end{aligned}
$$

The monthly averaged wind stress anomaly vectors from the ERA-Interim data were used to calculate $h^{\prime}(x, y, t)$. The wind force was zonally integrated along some latitudes in the North and South Pacific. These latitudes will be determined based on the result of the observation in section 3a. Also, values of each parameter will be given in section $3 b$.

\section{Results}

\section{a. Observations}

To obtain the overall features of the ocean waves associated with the ENSO events, monthly lead-lag regressions of the SSHA onto the Niño-3.4 index over the entire tropical Pacific were calculated (Fig. 1). The monthly lead-lag value is negative (positive) when the SSHA leads (lags) the Niño-3.4 index. Before the mature phase of an El Niño event at a lead-lag value of -6 months, a positive SSHA with an amplitude of $5 \mathrm{~cm}$ is dominant over the central and eastern portions of the equatorial Pacific. At lead-lag values from -6 to 0 months, the positive SSHA propagates eastward along the equator, exhibiting the eastward propagation of a downwelling Kelvin wave. After the mature phase of an El Niño event at a lead-lag value of +3 months, the equatorial Kelvin wave begins to decay in the eastern coastal boundary region. At a lead-lag value of +6 months, local maxima of positive SSHAs are formed at latitudes of $3^{\circ}-15^{\circ} \mathrm{N}$ and $4^{\circ}-10^{\circ} \mathrm{S}$, indicating downwelling Rossby wave formation as discussed in the introduction. At a lead-lag value of +12 months, the offequatorial SSHA ridge in the North Pacific further extends to the region west of $180^{\circ}$, whereas the SSHA ridge in the South Pacific begins to decay. These different features in the westward extensions in the North and South Pacific have also been reported based on analysis using observed ocean heat content anomalies (Hasegawa et al. 2008). The polarity of the regressed anomalies discussed in the present study is reversed during La Niña events.

To explore the formation and propagation features for each ENSO event, we showed longitude-time diagrams of the observed SSHAs along the off-equatorial zonal belt at $11^{\circ} \mathrm{N}$ (Fig. 2a) and $8^{\circ} \mathrm{S}$ (Fig. 2b), together with the time series of the Niño-3.4 index (Fig. 2c). These latitudes were chosen because the off-equatorial ridges of the regressed SSHAs on either side of the equator were found at these latitudes after the mature phases of El Niño events (Fig. 1). In Fig. 2c, the polarities of the two observed SSHAs averaged over the eastern portion $\left(130^{\circ}-110^{\circ} \mathrm{W}\right)$ at both $11^{\circ} \mathrm{N}$ and $8^{\circ} \mathrm{S}$ are positive during El Niño events (yellow boxes in 1994, 1997/98, 2002, 2004, 2006, and 2009) and negative during La Niña events (green boxes in 1995/96, 1999/2000, 2007/ 08, and 2010/11). These ENSO-related SSHAs in the eastern portion often extend westward (Figs. 2a,b), indicating Rossby wave propagation, although it should be noted that the eastward-extending feature is pronounced during the period from 1998 to 2001 (Fig. 2b). The possible cause of this eastward-extending feature will be discussed in section $3 b$. All these aspects including the ENSO-related polarities of the SSHAs and the initial formations of the SSHAs away from the eastern coastal boundary were found at $9^{\circ}-13^{\circ} \mathrm{N}$ and $6^{\circ}-10^{\circ} \mathrm{S}$ as well (not shown).

According to Chelton and Schlax (1996), phase speed of the off-equatorial Rossby waves is $20 \mathrm{~cm} \mathrm{~s}^{-1}$ at $11^{\circ} \mathrm{N}$ and $50 \mathrm{~cm} \mathrm{~s}^{-1}$ at $8^{\circ} \mathrm{S}$, respectively. These phase speeds are shown as straight lines in Figs. $2 a$ and $2 b$ with yellow lines for El Niño events and green lines for La Niña events. The westward-propagating features for the aforementioned ENSO events mostly follow the phase 


\section{SSHA}
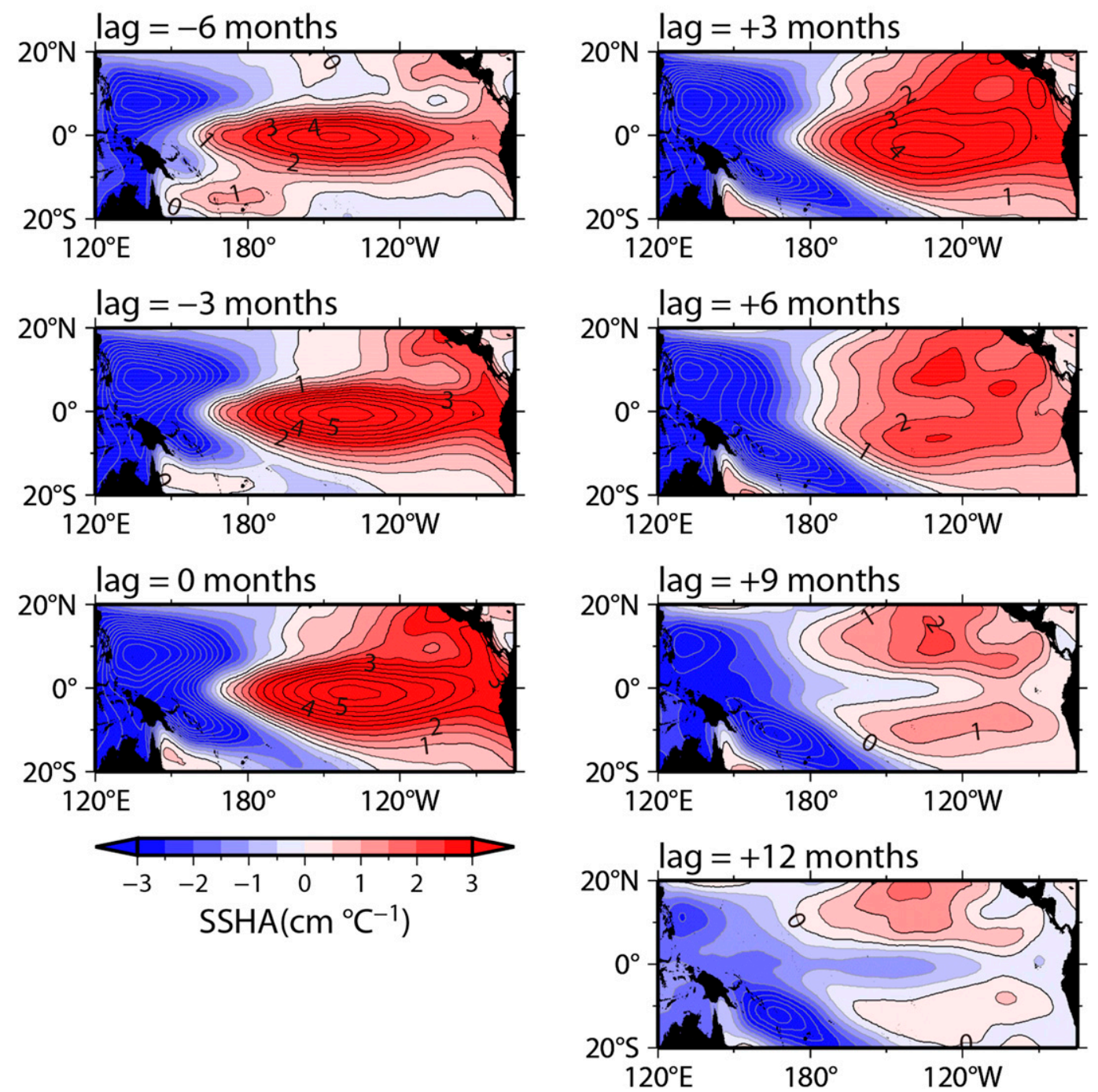

FIG. 1. Lead-lag regression maps of SSHAs onto Niño-3.4 index $\left(0.5 \mathrm{~cm}^{\circ} \mathrm{C}^{-1}\right.$ intervals $)$ at lead-lag values of -6 to +12 months in 3-month intervals. Monthly lead-lag values are negative (positive) when SSHA leads (lags) index. Shading convention is shown beneath.

speeds on either side of the equator. In addition to this qualitative comparison with the Chelton and Schlax's (1996) estimation speed, we quantitatively estimated propagation speeds from Figs. $2 a$ and $2 b$ through the method described in section $2 \mathrm{~b}$. The propagation speed, estimated with the use of the whole period of the SSHA data, was $30 \mathrm{~cm} \mathrm{~s}^{-1}$ at $11^{\circ} \mathrm{N}$. Likewise, it was $60 \mathrm{~cm} \mathrm{~s}^{-1}$ at $8^{\circ} \mathrm{S}$ using all data except for the 1998-2001 negative SSHA event. These values are close to those in Chelton and Schlax's (1996) values. As to the SSHA amplitude, all the SSHA events have the maximum amplitudes distant from the eastern coastal boundary except for the 1997/98 SSHA event. Therefore, in the present study, we examined the surface wind forcing in the interior region.
The regression coefficients of the WSCAs onto the Niño-3.4 index $\left(\times 10^{-4} \mathrm{~N} \mathrm{~m}^{-3} \mathrm{~s}^{\circ} \mathrm{C}^{-1}\right.$, color $)$ over the tropical Pacific are shown in Fig. 3. The WSCA is defined by the following equation:

$$
\mathrm{WSCA}=\nabla \times\left(\tau^{\prime} \mid f\right),
$$

where $\tau^{\prime}$ is the wind stress anomaly and $f$ is the Coriolis parameter. The regressed SSHA at a lead-lag value of +6 months is also superimposed on Fig. 3. No time lag is taken into consideration for the WSCA map in order to extract the ENSO-related signals, while we considered the time lag for the SSHA map because the strong SSHA signal of the equatorial Kelvin wave, which masks 

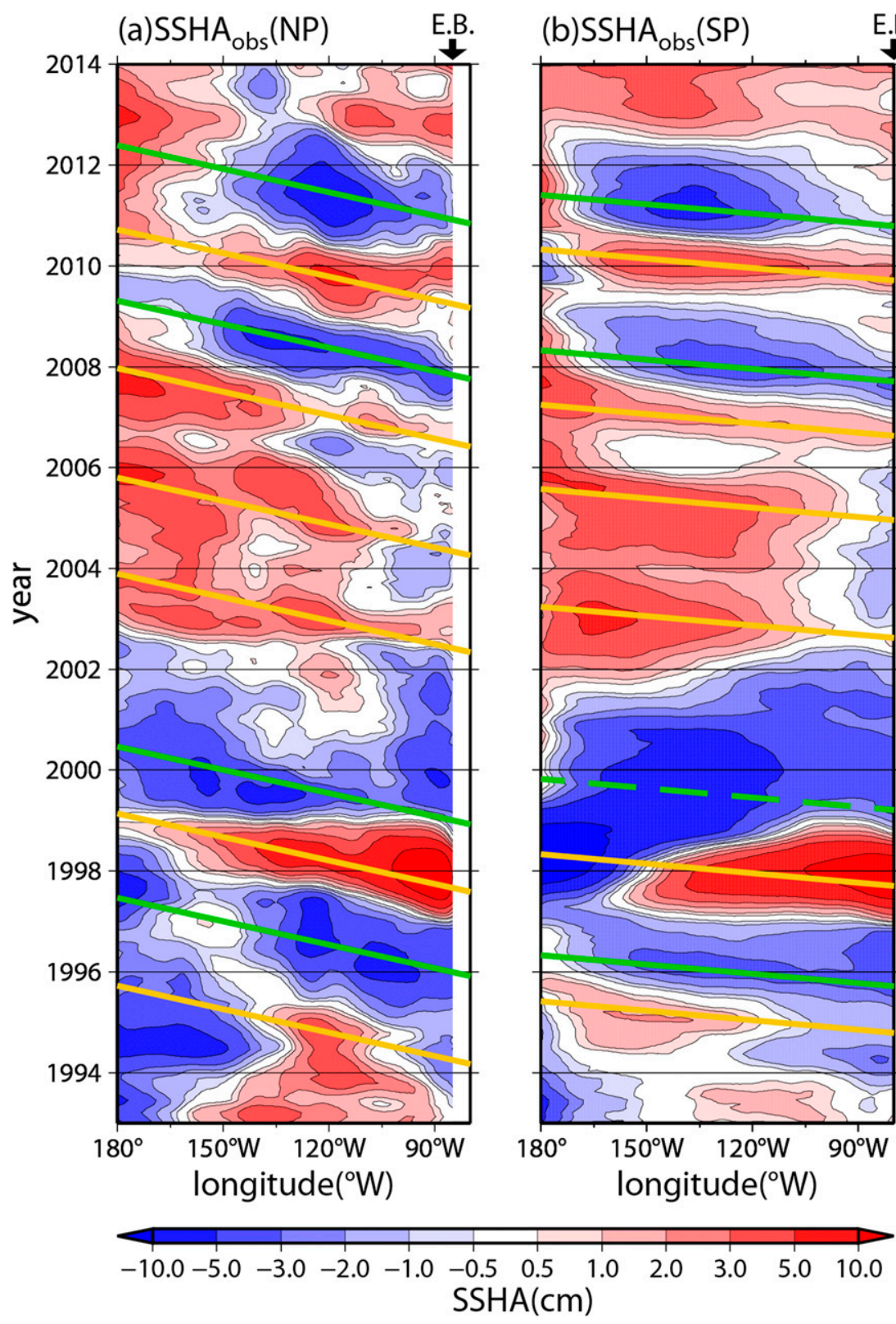
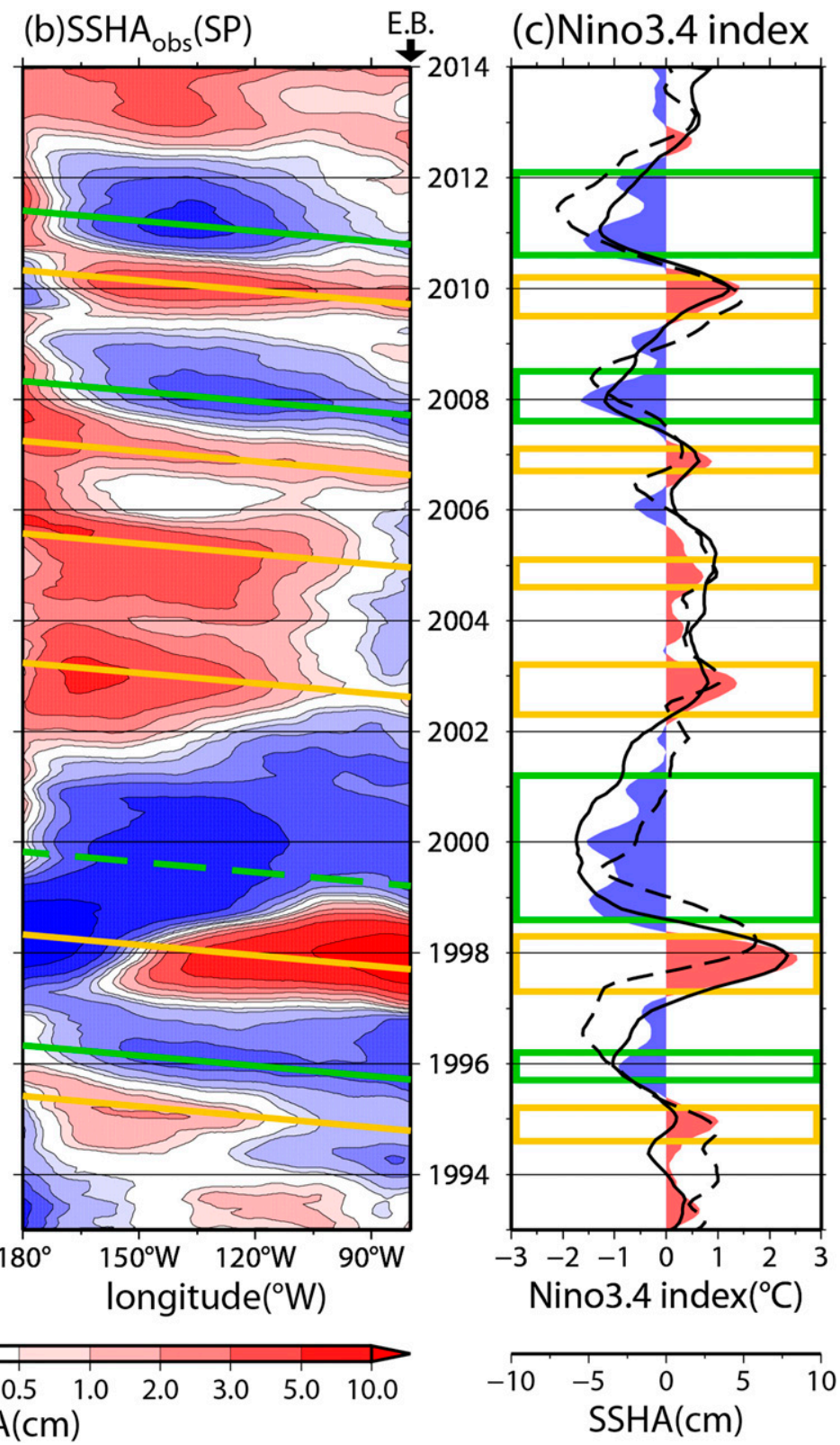

FIG. 2. Hovmöller diagrams of observed SSHAs (cm) along (a) $11^{\circ} \mathrm{N}$ and (b) $8^{\circ} \mathrm{S}$. A 13 -month, running-mean filter is applied to the SSHAs after it is smoothed by a Gaussian filter with an $e$-folding scale of $300 \mathrm{~km}$. Shading convention is shown beneath. Straight lines superposed on diagrams are indicators of Rossby wave propagation speeds of $20 \mathrm{~cm} \mathrm{~s}^{-1}$ in (a) and $50 \mathrm{~cm} \mathrm{~s}^{-1}$ in (b). (c) Time series of Niño3.4 index (color) and those of SSHAs (black lines) calculated by zonally averaging over $130^{\circ}-110^{\circ} \mathrm{W}$ at $11^{\circ} \mathrm{N}$ (dashed line) and $8^{\circ} \mathrm{S}$ (solid line). El Niño (La Niña) events are shown by yellow (green) boxes. Straight lines in Figs. 2a and $2 \mathrm{~b}$ are positioned so that they pass through specific longitudes $\left(120^{\circ} \mathrm{W}\right.$ or central longitude of $\left.130^{\circ}-110^{\circ} \mathrm{W}\right)$ and times (when major peaks of SSHAs in Fig. $2 \mathrm{c}$ are observed).

off-equatorial ocean response to the wind forcing, still remained 3 months after the mature phase of the ENSO event. In the North Pacific, a negative WSCA is evident along the off-equatorial zonal belt from $8^{\circ}$ to $14^{\circ} \mathrm{N}$ in the eastern portion of the basin. Likewise, in the South Pacific, a negative WSCA is evident along the offequatorial zonal belt from $3^{\circ}$ to $15^{\circ} \mathrm{S}$. We made the same figure in which long-term trends were removed, but the same anticyclonic structures of both hemispheres were obtained (not shown). Our additional analysis of 2000-08 QuikSCAT data and 1993-2013 NCEP-NCAR Reanalysis-1 (Kalnay et al. 1996) and an analysis of 1962-2009 ECMWF Ocean Reanalysis, System 3 (ORA-S3), wind data by Qiu and Chen (2010) also 


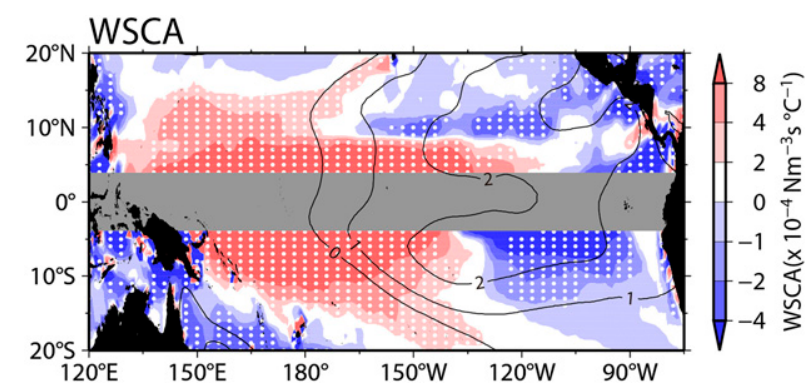

FIG. 3. Regression map of WSCAs $\left(\times 10^{-4} \mathrm{~N} \mathrm{~m}^{-3} \mathrm{~s}^{\circ} \mathrm{C}^{-1}\right.$, color $)$ onto Niño-3.4 index at a lead-lag value of 0 months. White dots denote locations at which regression coefficients are statistically significant exceeding a $10 \%$ significance level. Equatorial area at $3^{\circ} \mathrm{S}-3^{\circ} \mathrm{N}$ is masked by gray due to small Coriolis parameter. Shading convention is shown at right. The color scale is not symmetric to emphasize the negative values of the regression coefficient. Regressed SSHAs at a lead-lag value of +6 months, as shown in Fig. 1, are superposed $\left(\mathrm{cm}^{\circ} \mathrm{C}^{-1}\right.$, contours).

revealed anticyclonic WSCAs in the off-equatorial belts on either side of the equator over the eastern tropical Pacific (not shown), as shown in Fig. 3 based on the ERA-Interim data. Clarke (2008) carried out the same analysis using the European Remote Sensing Satellite (ERS) wind for the period of 1992-2008 and found weak anticyclonic WSCAs in the eastern tropical North and South Pacific. White dots in Fig. 3 denote locations at which regression coefficients are statistically significant exceeding a $10 \%$ significance level [or equivalently within a confidence limit of $90 \%$ (Hasegawa et al. 2007)]. As indicated by the white dots, the regressed WSCAs in the eastern tropical Pacific are statistically significant. Also, explained variance of the WSCAs, defined by the ratio of variance of the ENSO-related WSCAs to the variance of the 13-month running-mean filtered WSCAs, was more than $25 \%$ with the maximum ratio of $37 \%$ in the North Pacific and $53 \%$ in the South Pacific (not shown).

A role of the wind-induced Ekman pumping on upper-ocean dynamics was examined for the seasonal thermocline variability in the western South Pacific by Holbrook and Bindoff (1999) and for the interannual thermocline variability in the whole Pacific basin by Perkins and Holbrook (2001). Indeed, Fig. 3 displays that the off-equatorial ridges of the SSHA and the overlying anticyclonic WSCAs are mostly on the same latitudes of $11^{\circ} \mathrm{N}$ and $8^{\circ} \mathrm{S}$. While the 6-month difference of the time lag between the SSHAs and WSCAs indicates the 6-month temporal evolution of the SSHA ridges formed after the appearance of the negative WSCAs, the formation process will be examined in the next subsection. In the western tropical Pacific, positive WSCAs contributing to the negative SSHA formations in the same region were found (Fig. 1), as investigated by Weisberg and Wang (1997) and Qiu and Chen (2010). However, the westward propagation of the SSHAs in Fig. 2 starts from the eastern tropical Pacific. Therefore, in section 3b, we will discuss the influence of WSCAs in the eastern tropical Pacific on the formation of the Rossby waves using a simple Rossby wave model.

\section{b. A 1.5-layer Rossby wave model}

The westward extensions of the off-equatorial SSHAs from the negative WSCA regions in the eastern tropical Pacific on either side of the equator (Fig. 3) indicated that the Rossby waves were induced by surface wind forcing in the same region. To examine whether negative (positive) WSCAs along the off-equatorial belts in the North and South Pacific sectors during the mature phases of El Niño (La Niña) events can generate downwelling (upwelling) Rossby waves, a 1.5-layer baroclinic Rossby wave model was employed (see section 2c). The wind forcing was zonally integrated along $11^{\circ} \mathrm{N}\left(8^{\circ} \mathrm{S}\right)$ for the North Pacific (South Pacific). The value of $g^{\prime}$ was $0.05 \mathrm{~m} \mathrm{~s}^{-2}$ (Qiu and Chen 2010), $1 / \varepsilon$ was $0.5 \mathrm{yr}$ (Picaut et al. 1993; Qiu and Chen 2010), and $x_{E}$ was $85^{\circ} \mathrm{W}$ at $11^{\circ} \mathrm{N}$ and $80^{\circ} \mathrm{W}$ at $8^{\circ} \mathrm{S}$. To examine only the wind effect, the first term on the right-hand side of Eq. (2) was set to zero. The propagation speed $C_{R}$ was $20 \mathrm{~cm} \mathrm{~s}^{-1}$ at $11^{\circ} \mathrm{N}$ and $50 \mathrm{~cm} \mathrm{~s}^{-1}$ at $8^{\circ} \mathrm{S}$ by referencing the values in Chelton and Schlax (1996) (see Fig. 5 of their work).

The result of the Rossby wave model forced by the wind stress anomaly is shown in Fig. 4. Longitude-time diagrams of the simulated SSHAs along the offequatorial zonal belt at $11^{\circ} \mathrm{N}$ and $8^{\circ} \mathrm{S}$ are shown in Figs. $4 \mathrm{a}$ and $4 \mathrm{~b}$, respectively. Visual inspection of Figs. 2 and 4 indicates that the simulations well reproduce the observed westward-propagating features of the SSHAs as well as the eastward-extending feature from 1998 to 2001 at $8^{\circ} \mathrm{S}$. Similar formation and propagation features of the Rossby waves were obtained in a realistic range of the parameter values of $g^{\prime}=(0.05 \pm 0.01) \mathrm{m} \mathrm{s}^{-2}, C_{R}=$ $(20 \pm 10) \mathrm{cm} \mathrm{s}^{-1}$ at $11^{\circ} \mathrm{N}\left[(50 \pm 25) \mathrm{cm} \mathrm{s}^{-1}\right.$ at $\left.8^{\circ} \mathrm{S}\right]$, and $1 / \varepsilon=0.25-\infty \mathrm{yr}$. In addition, these features were found in the simulated SSHAs at $9^{\circ}-13^{\circ} \mathrm{N}$ and $6^{\circ}-10^{\circ} \mathrm{S}$ as well (not shown).

The formation areas of the positive SSHAs in the original experiment are not fixed at a specific longitude, but they display the zonal shift from $100^{\circ}-135^{\circ} \mathrm{W}$ in the 1990 s to $110^{\circ}-150^{\circ} \mathrm{W}$ in the 2000 s (Figs. $4 \mathrm{a}, \mathrm{b}$ ). This zonal shift is also hinted at in Figs. 2a and 2b. Several recent studies reported that different type of El Niño events, so-called El Niño Modoki (Ashok et al. 2007) or its similar events (Larkin and Harrison 2005; Yu and Kao 2007; Kug et al. 2009), were frequently observed in the 2000s (Singh et al. 2011). During this different type of El 

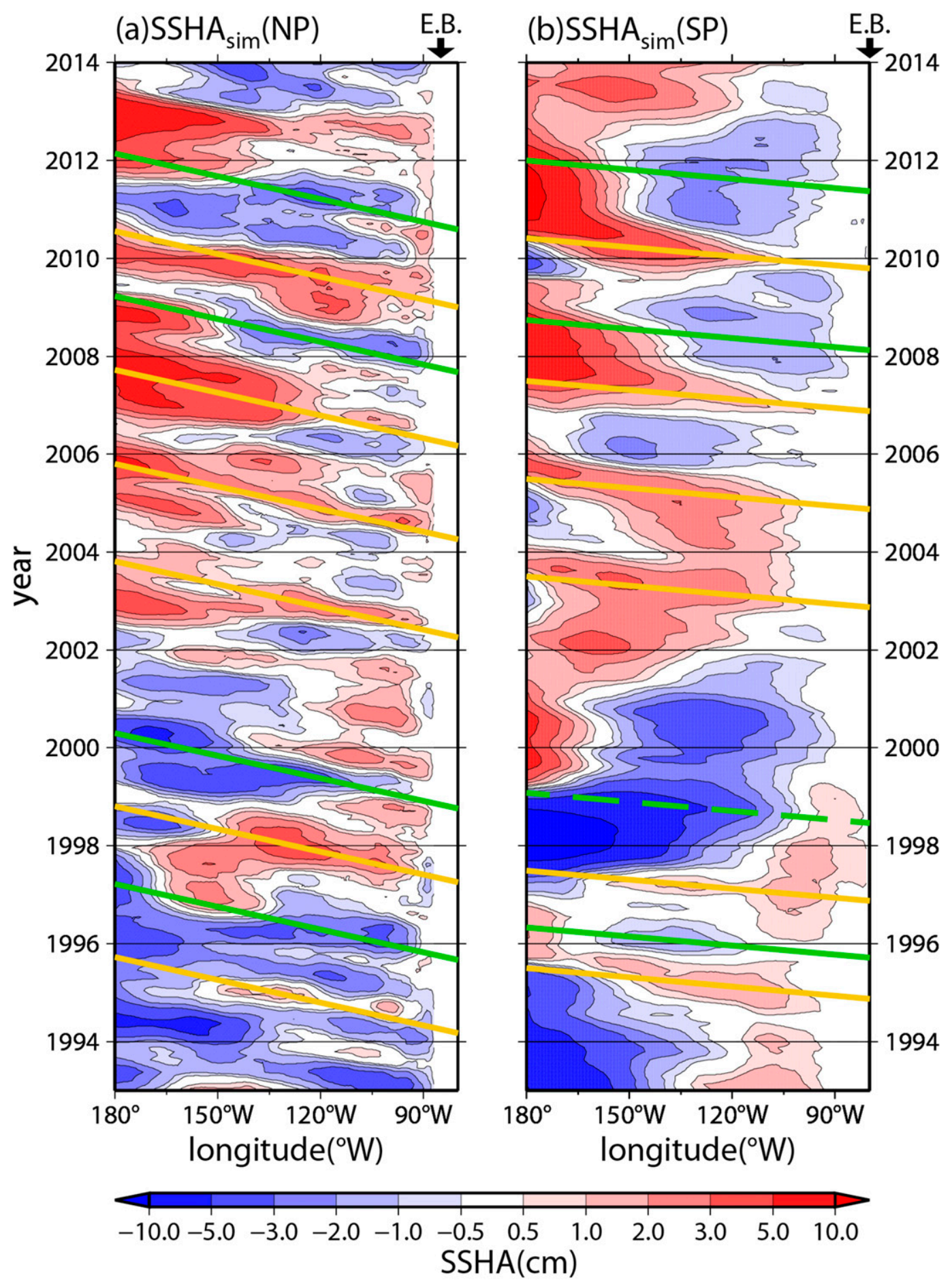

FIG. 4. (a),(b) As in Fig. 2, but calculated using simulated SSHAs given by the reduced-gravity model in Eq. (2).

Niño events, the local maxima of positive sea surface temperature anomalies (SSTAs) are located in the central Pacific rather than in the eastern Pacific. Ashok et al. (2007) noted the zonal shifts of the negative sea level pressure anomalies (SLPAs) and associated surface wind anomalies. The zonal shift in the area wherein positive SSHA is formed in the experiment is affected by the shift in the surface wind forcing. In fact, the negative WSCAs in the 1990s were often found east of $150^{\circ} \mathrm{W}$, while those in the 2000 s tend to be west of 
$120^{\circ} \mathrm{W}$ (not shown). However, the zonal shift is not obvious in the negative SSHAs during La Niña events. This result is consistent with the fact that no zonal shift of the negative SSTAs occurs in the 2000s.

We calculated statistics using the simulated SSHAs and observed SSHAs (Fig. 5). The simultaneous correlation coefficients between the simulated and observed SSHAs on each of the two longitude-time diagrams are significant west of $120^{\circ} \mathrm{W}$ for $11^{\circ} \mathrm{N}$ (Fig. 5a) and for $8^{\circ} \mathrm{S}$ (Fig. 5b), exceeding a $10 \%$ significance level. In addition, the correlation coefficients increase to the west along these two latitudes. These findings are consistent with the findings of Perkins and Holbrook (2001). The high correlation coefficients over the central to western portion of the domain reflect the importance of the WSCAs in forcing Rossby waves in $180^{\circ}-120^{\circ} \mathrm{W}$ while the lower correlations in the east portion of the domain in $120^{\circ}-80^{\circ} \mathrm{W}$ suggest that other processes, including the Rossby wave emissions from the eastern coastal boundary, are at work (see Perkins and Holbrook 2001). The westward increases in the correlation coefficients indicate that the wind effect in SSHA generation is more important in the interior region far from the coast in $180^{\circ}-120^{\circ} \mathrm{W}$, or, equivalently, the influence of the reflected equatorial Kelvin wave onto the off-equatorial Rossby waves decreases westward.

Similar statistical behaviors of the correlation coefficients were found for the correlation coefficients calculated without considering the 1997/98 El Niño event (the coefficients were $0.83,0.62,0.42$, and 0.11 at $180^{\circ} \mathrm{W}$, $150^{\circ} \mathrm{W}, 120^{\circ} \mathrm{W}$, and $90^{\circ} \mathrm{W}$ along $11^{\circ} \mathrm{N}$, respectively; 0.73 , $0.58,0.75$, and -0.13 at the same longitudes along $8^{\circ} \mathrm{S}$ ), indicating the calculated correlation coefficient is not affected by the extremely large value of the SSHA in 1997/98. In addition, longitudinal plots of the correlation coefficients at the nearby latitudes $\left(9^{\circ}-13^{\circ} \mathrm{N}\right.$ and $\left.6^{\circ}-10^{\circ} \mathrm{S}\right)$ showed both the westward increase of the coefficients (not shown) and the high coefficients $(0.44,0.56,0.66$, 0.70 , and 0.71 at $9^{\circ}, 10^{\circ}, 11^{\circ}, 12^{\circ}$, and $13^{\circ} \mathrm{N}$ and $0.66,0.66$, $0.65,0.66$, and 0.67 at $6^{\circ}, 7^{\circ}, 8^{\circ}, 9^{\circ}$, and $10^{\circ} \mathrm{S}$ in $180^{\circ}-120^{\circ} \mathrm{W}$ on average) as shown in Figs. 5a and 5b.

Root-mean-square difference (RMSD) between the simulated and observed SSHAs, root-mean-square (RMS) of the simulated SSHAs, and RMS of the observed SSHAs are shown in Figs. 5c and 5d. The RMSD is regarded as a representative value of the difference between the simulated SSHAs and observed SSHAs, so a large RMSD value indicates the model performance is not good, while a small RMSD value means the simulation goes well. The simulated SSHA (dotted line) at $11^{\circ} \mathrm{N}$ shows westward increase of the RMS reaching up to $3-4 \mathrm{~cm}$ at $180^{\circ} \mathrm{W}$. The similar westward increase of the simulated SSHA, with the maximum value of $6-7 \mathrm{~cm}$, is found at $8^{\circ} \mathrm{S}$. The observed SSHA at $11^{\circ} \mathrm{N}$ and $8^{\circ} \mathrm{S}$ (dashed lines) also shows similar westward increase of the RMS, although the value is large near the eastern coastal boundary due to the boundary signal as explained in Fig. 2. The RMSD at $11^{\circ} \mathrm{N}$ (solid line) largely decreases to the west in $135^{\circ}-85^{\circ} \mathrm{W}$, while it keeps the minimum value of $2 \mathrm{~cm}$ in $180^{\circ}-135^{\circ} \mathrm{W}$. The RMSD at $8^{\circ} \mathrm{S}$ also decreases to the west in $120^{\circ}-80^{\circ} \mathrm{W}$, while it then turns to the westward increase in $180^{\circ}-135^{\circ} \mathrm{W}$. Since the RMSD is largely dependent on the SSHA amplitude itself, we normalized the RMSD by dividing it by the average of the RMS of the observed SSHA and the RMS of the simulated SSHA (Figs. 5e,f). The normalized RMSD shows westward decrease, reaching to the level below 1.0 in $180^{\circ}-130^{\circ} \mathrm{W}$ at both $11^{\circ} \mathrm{N}$ and $8^{\circ} \mathrm{S}$. This fact indicates successful simulation of the SSHAs in the interior region in $180^{\circ}-130^{\circ} \mathrm{W}$.

In the employed model, we assumed that the $g^{\prime}$ is constant at $11^{\circ} \mathrm{N}$ and $8^{\circ} \mathrm{S}$, which indicates the thermocline depth is constant at these latitudes. The $g^{\prime}$ value of $0.05 \mathrm{~m} \mathrm{~s}^{-2}$ is used in Qiu and Chen (2010), which examines SSH variability in the interior region of tropical Pacific where the thermocline depth is relatively deep. However, its depth is much shallower in the near-coastal boundary region than in the interior region. For this reason, the SSHA response to the wind forcing in the near boundary region is expected to be overestimated in the model because of the larger $g^{\prime}$ in the model compared to reality. Therefore, the amplitude of the simulated SSHAs in the near-boundary region becomes smaller when the shallower thermocline depth is taken into consideration in the model.

Following Perkins and Holbrook (2001), we conducted an additional simulation wherein the remote effect from the Rossby waves was excluded; in practice, the second term on the left-hand side of Eq. (1) was removed. Thus, Ekman pumping by the surface wind anomalies is the only factor responsible for SSHA formation in this additional experiment. In such an experiment, we can indirectly diagnose how important the remotely forced Ekman pumping effect is for the determination of the observed SSHAs. As expected from the model settings of the additional experiment, the westward-propagating feature found in the observations and original simulation mostly disappears (Figs. 6a,b). However, the eastward-extending feature still remains in Fig. 6b, indicating that the signals during 1998-2001 is a result of the local wind stress curl effect.

The simultaneous correlation coefficients between the results of the simulations performed in the additional experiment and the observations are insignificant in $90^{\circ}$ $110^{\circ} \mathrm{W}$ and $120^{\circ}-150^{\circ} \mathrm{W}$ at $11^{\circ} \mathrm{N}$ (Fig. $6 \mathrm{c}$ ) and most of the longitudes at $8^{\circ} \mathrm{S}$ (Fig. 6d). This poor reproducibility in 

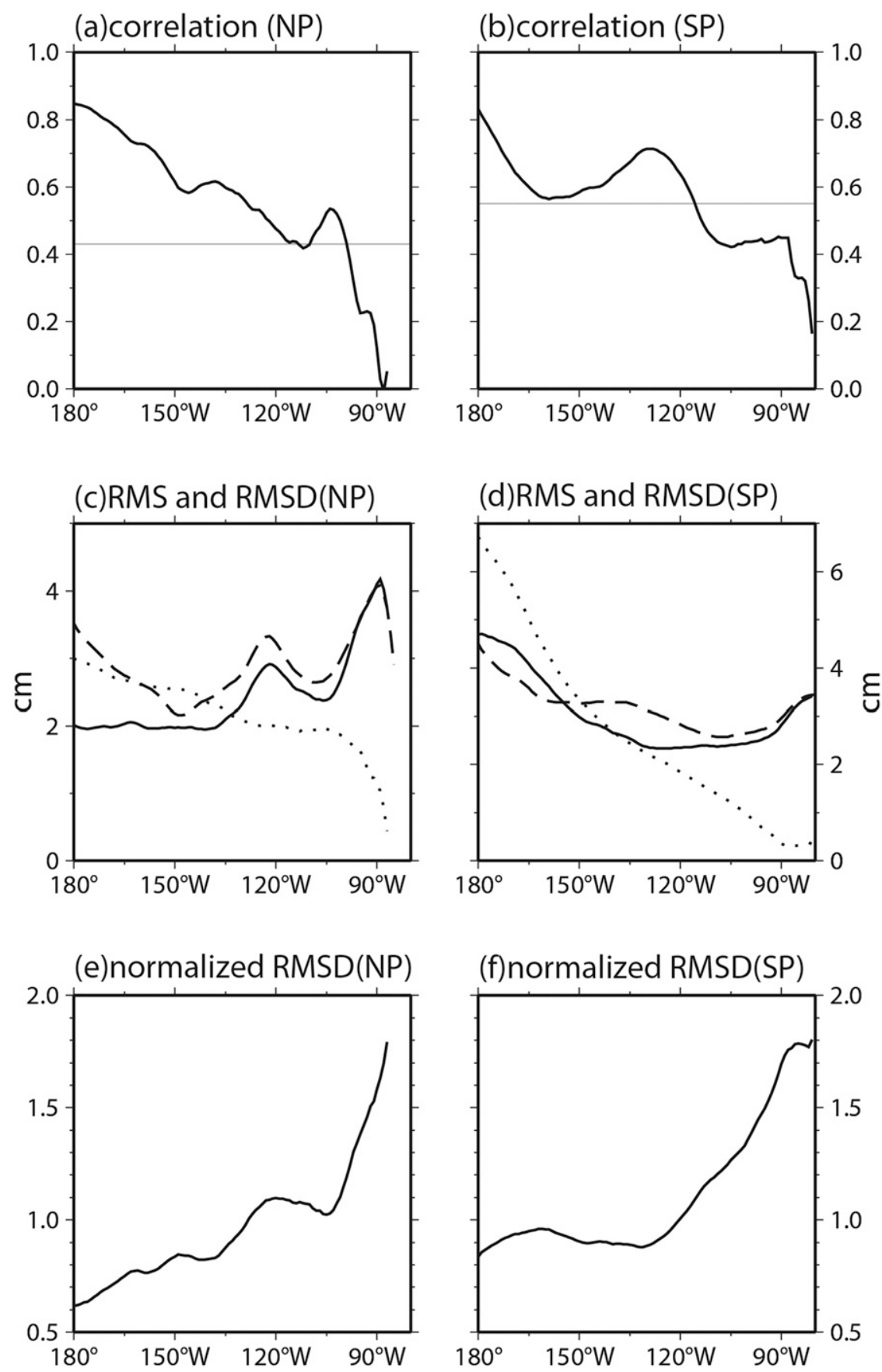

FIG. 5. Longitudinal plot of statistic values at (left) $11^{\circ} \mathrm{N}$ and (right) $8^{\circ} \mathrm{S}$. (a),(b) Simultaneous correlation coefficient of the simulated SSHAs (Fig. 4) with observed SSHAs (Fig. 2). The horizontal line in each figure indicates a $10 \%$ significance level of the correlation coefficients. (c),(d) RMSD between the observed and simulated SSHAs (solid line), RMS of the observed SSHAs (dashed line), and RMS of the simulated SSHAs (dotted line). The vertical range is not same between (c) and (d). (e),(f) Normalized RMSD calculated by dividing the RMSD by average of the RMS of the observed SSHAs and RMS of the simulated SSHAs in Figs. $5 c$ and $5 d$. 

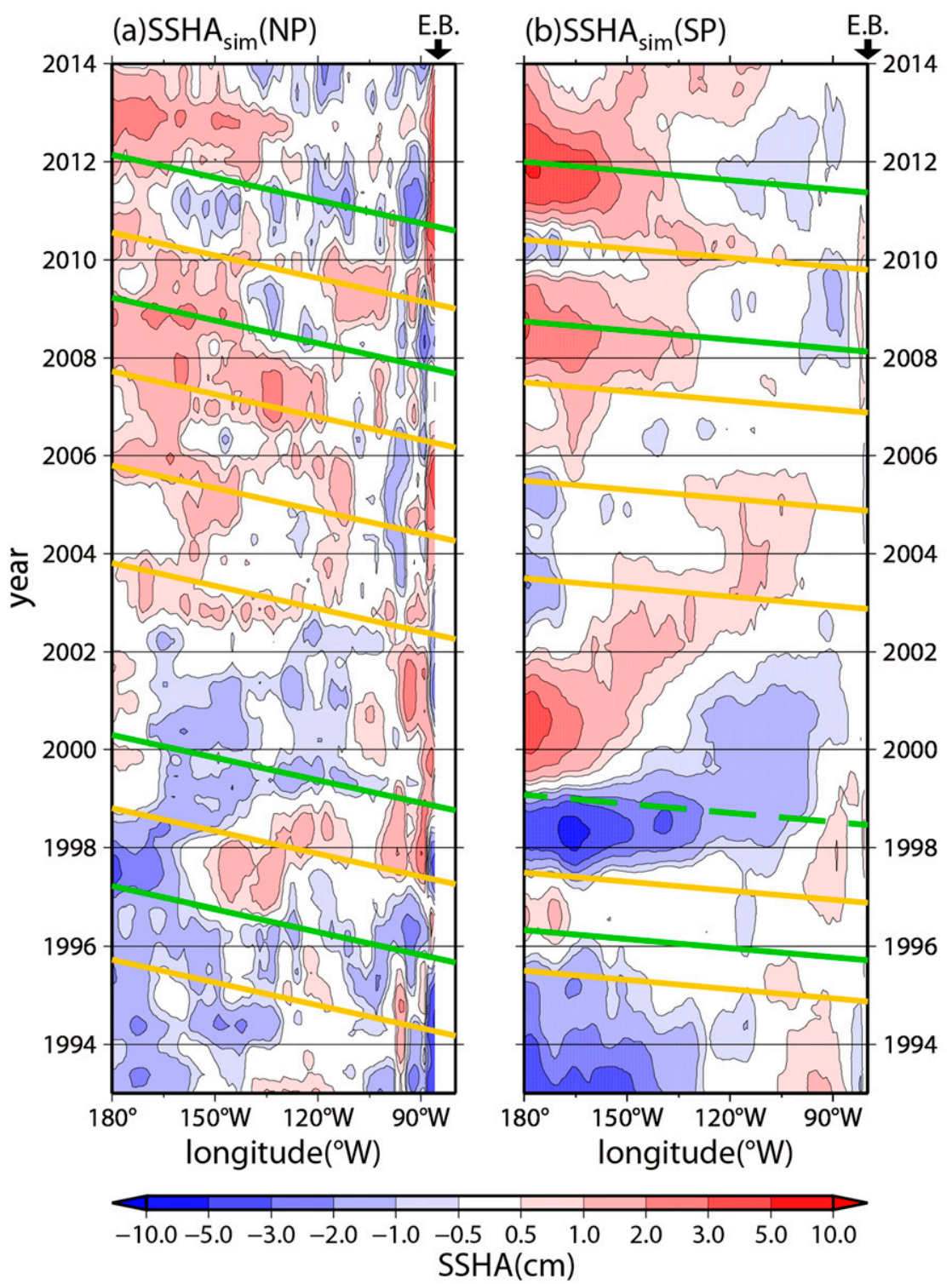

2006

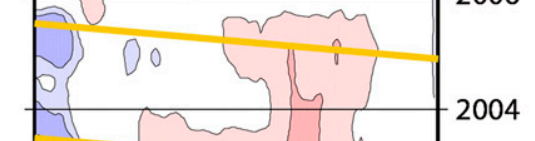

(c)correlation(NP)

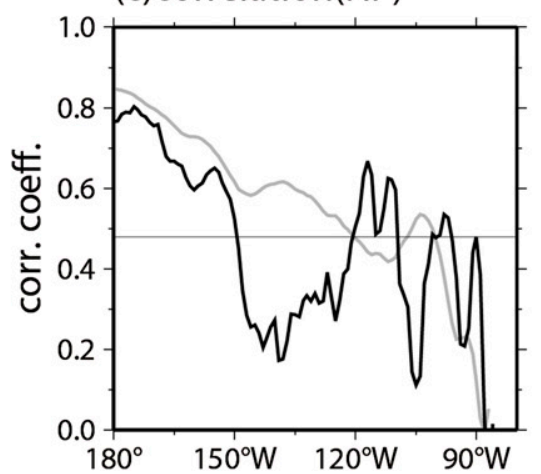

(d)correlation(SP)

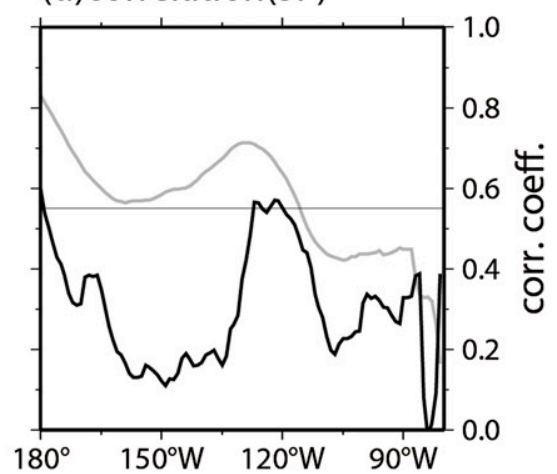

FIG. 6. (a),(b) As in Fig. 4, but given by reduced-gravity model driven under condition that $C_{R}$ in Eq. (1) is $0 \mathrm{~cm} \mathrm{~s}^{-1}$. Simultaneous correlation coefficients of simulated SSHAs (Fig. 6) with observed SSHAs (Fig. 2) at (c) $11^{\circ} \mathrm{N}$ and (d) $8^{\circ} \mathrm{S}$ (black lines) as functions of longitude. Gray lines in (c) and (d) are identical to those in Figs. 5a and 5b, respectively. 
the additional experiment is due to a lack of Rossby wave dynamics. These intercomparisons between the simulated results of the original and additional experiments strongly suggest that knowledge of the spatial patterns in the surface wind anomalies formed during ENSO events and their effect on ocean waves is necessary to obtain the off-equatorial SSHAs on either side of the equator.

\section{c. Meridional shear of anomalous easterly winds}

In consideration of the observed and simulated SSHAs, it is evident that the formations of the ENSOrelated off-equatorial Rossby waves in $180^{\circ}-120^{\circ} \mathrm{W}$ are induced by anomalous Ekman pumping in $135^{\circ}-90^{\circ} \mathrm{W}$. This finding suggests that the off-equatorial WSCAs on either side of the equator are linked to the same atmospheric circulation straddling the equator. Figure 7 displays the regression map of the (Fig. 7a) SSTAs, (Fig. 7b) SLPAs, and (Fig. 7c) surface wind vector anomalies onto the Niño-3.4 index. Again, the reason for showing the regression coefficients with the time lag not considered is to extract the ENSO-related signals. The most striking feature in Fig. 7a is an equatorially symmetric pattern of positive SSTAs in the eastern portion of the equatorial Pacific, which is a well-known SSTA pattern during the mature phase of an El Niño event. Because of the hydrostatic response of the lower atmosphere to the warm SSTAs in the eastern Pacific, negative SLPAs are formed over the eastern portion of the tropical Pacific (Fig. 7b). Our inspection of the individual SLPA maps showed that this SLPA pattern with a negative (positive) center of action on the equator was observed in all the El Niño events (all the La Niña events). The value at the center was $-30,-180,-60,-30,-20$, and -60 Pa for the 1994 , 1997/98, 2002, 2004, 2006, and 2009 El Niño events, while it was $+70,+100,+60$, and $+90 \mathrm{~Pa}$ for the $1995 /$ 96, 1999/2000, 2007/08, and 2010/11 La Niño events. The amplitude for the 1997/98 El Niño event was extremely large. By contrast, the western Pacific is characterized by positive SLPAs because the underlying SSTAs are cooler than normal. Because of these basin-scale SLP changes, distinct westerly anomalies of more than $1 \mathrm{~m} \mathrm{~s}^{-1}{ }^{\circ} \mathrm{C}^{-1}$ blow toward the center of negative SLPAs in the equatorial region west of $135^{\circ} \mathrm{W}$, whereas in the eastern Pacific east of $135^{\circ} \mathrm{W}$, easterly anomalies of less than $0.5 \mathrm{~m} \mathrm{~s}^{-1}{ }^{\circ} \mathrm{C}^{-1}$ blow toward the center of the negative SLPAs (Fig. 7c). Although the easterly anomalies in the eastern tropical Pacific are weak, significant anticyclonic WSCAs were evident around the regions (Fig. 3). These easterly anomalies have been observed during El Niño Modoki events as well (Ashok et al. 2007). Previous studies intensively investigated the roles

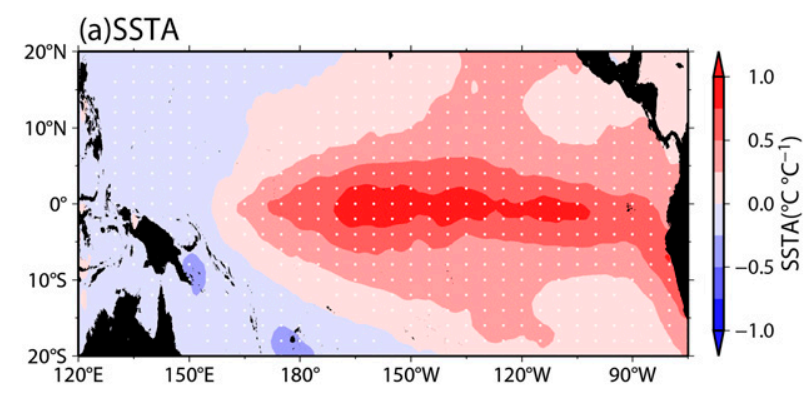

(b)SLPA
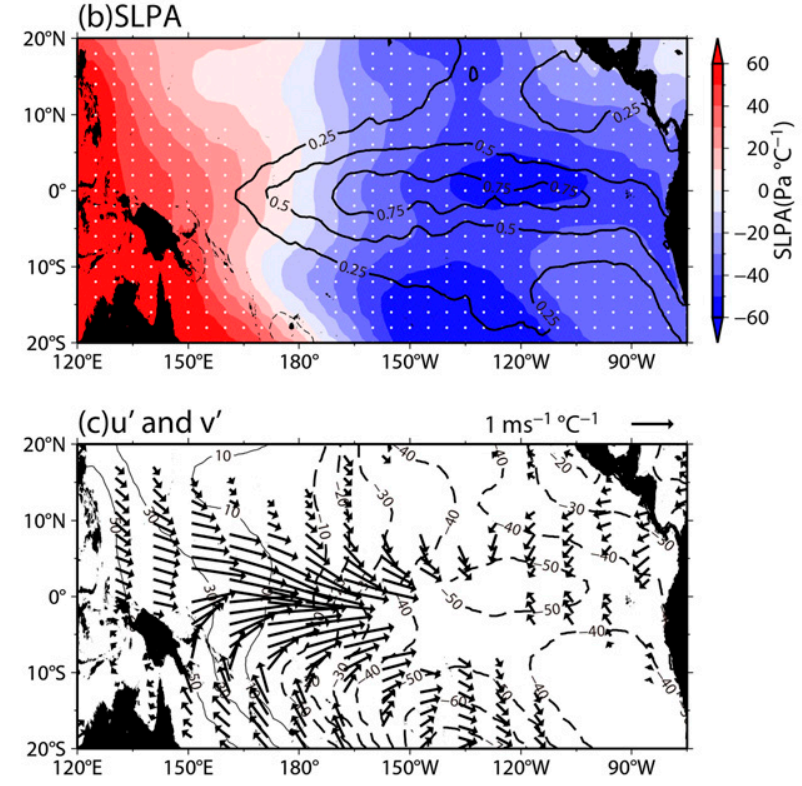

FIG. 7. Regression map of (a) $\operatorname{SSTAs}\left({ }^{\circ} \mathrm{C}^{\circ} \mathrm{C}^{-1}\right.$, color), (b) SLPAs $\left(\mathrm{Pa}{ }^{\circ} \mathrm{C}^{-1}\right.$, color), and (c) surface wind vector anomalies $\left(\mathrm{m} \mathrm{s}^{-1}{ }^{\circ} \mathrm{C}^{-1}\right.$, arrows) onto Niño-3.4 index at a lead-lag value of 0 months. Shading convention is shown at right. White dots in (a) and (b) denote locations at which regression coefficients are statistically significant exceeding a $10 \%$ significance level. The regressed wind vectors in (c) are plotted only when both of the $x$ and $y$ components exceed a $10 \%$ significance level. The contour maps in (b) and (c) are different forms of the color maps in (a) and (b), respectively.

of the strong westerly anomalies on the formation of equatorial Kelvin waves in the western Pacific (e.g., McPhaden and Yu 1999). However, the influences of easterly anomalies on ocean wave formations in the eastern Pacific have not been fully addressed.

The regressions of WSCAs, wind stress anomalies, and SLPAs onto the Niño-3.4 index over the eastern Pacific $\left(140^{\circ}-75^{\circ} \mathrm{W}\right)$, where the easterly anomalies are pronounced, are shown in Fig. 8a. The lower two panels of Fig. 8 show the regressed anomalies using only the zonal and meridional components of wind stress, respectively, that is, $\tau^{\prime x}$ and $-\partial\left(\tau^{\prime x} / f\right) / \partial y$ and (Fig. 8b) and $\tau^{\prime y}$ and $\partial\left(\tau^{\prime y} / f\right) / \partial x$ (Fig. 8c). As expected from the surface wind anomalies in Fig. 7, the wind stress anomalies over the eastern Pacific are mostly directed toward the center of 

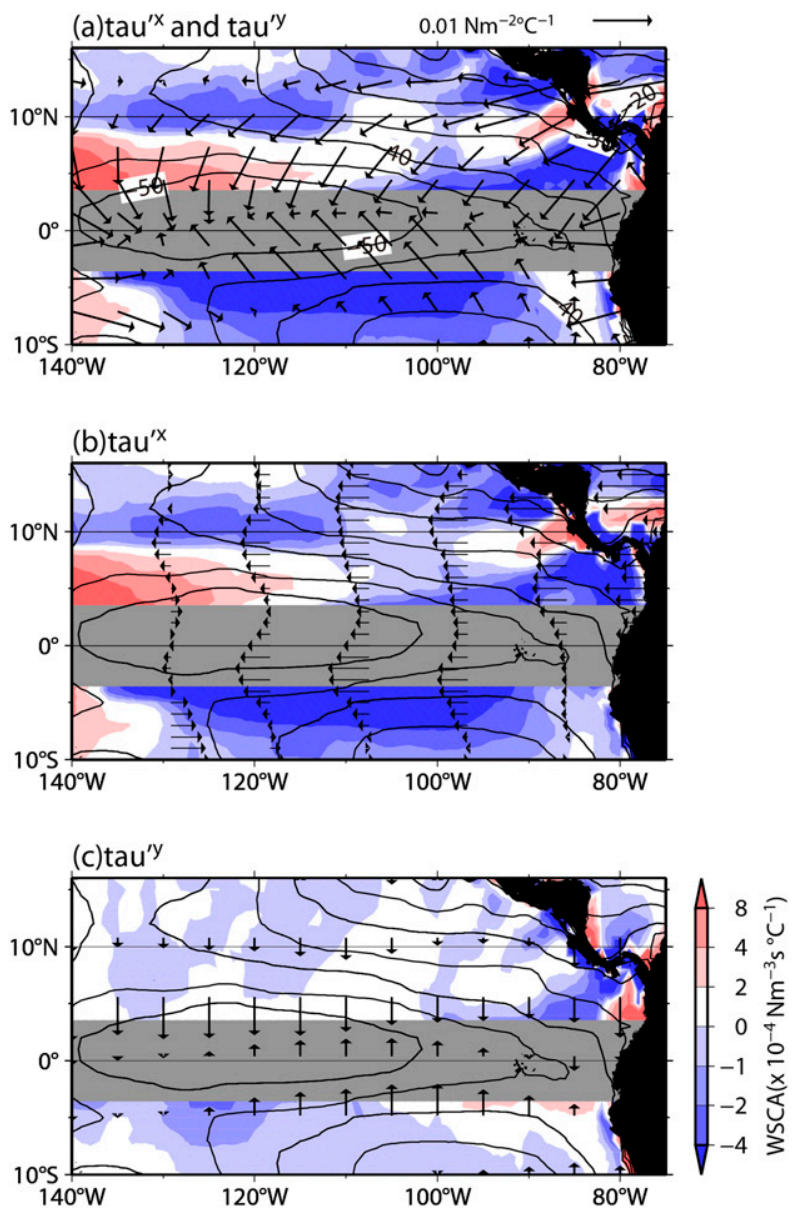

FIG. 8. (a) Regression map of WSCAs (color, $\times 10^{-4} \mathrm{~N} \mathrm{~m}^{-3} \mathrm{~s}^{\circ} \mathrm{C}^{-1}$ ) onto Niño-3.4 index, superimposed with regression of wind stress anomalies (arrows, $\mathrm{N} \mathrm{m}^{-2}{ }^{\circ} \mathrm{C}^{-1}$ ) and SLPAs (contours, $\mathrm{Pa}^{\circ} \mathrm{C}^{-1}$ ). (b),(c) Regression maps only using zonal and meridional components of wind stress anomalies, respectively, that is, $\tau^{\prime x}$ and $-\partial\left(\tau^{\prime x} / f\right) / \partial y$ (Fig. 8b) and $\tau^{\prime y}$ and $\partial\left(\tau^{\prime y} / f\right) / \partial x$ (Fig. 8c). Shading convention is shown beneath. Equatorial area at $3^{\circ} \mathrm{S}-3^{\circ} \mathrm{N}$ is masked by gray due to small Coriolis parameter.

the negative SLPAs. While no distinct WSCAs are evident near this SLPA center, the zonal belts of negative WSCAs are located in the off-equatorial regions on either side of the equator wherein meridional gradients of the SLPAs are observed.

An overall comparison of Figs. 8a, 8b, and 8c shows that the meridional gradients of the zonal components of the wind stress anomalies contribute significantly to the total amount of the WSCAs in the off-equatorial zonal belts. The plotted SLPA contours indicate that these offequatorial zonal components of wind stress anomalies are associated with the geostrophic zonal wind (Fig. 8b). The directions of the meridional components of the wind stress anomalies on either side of the equator are equatorward and across the isobars toward the center of the SLPA, indicating ageostrophic components (Fig. 8c). However, the zonal gradients of the meridional components of the wind stress anomalies contribute little to the total amount of the WSCAs.

We assume that anomalous surface wind velocities are mostly attributed to geostrophic components calculated from the spatial pattern of SLPAs in Fig. 8. If this assumption is valid, one may expect that the Laplacian of the eastern Pacific SLPAs, which is regarded as surface wind vorticity, will represent the off-equatorial zonal bands of the WSCAs on either side of the equator. Figure 9a displays the regressed anomalies of the Laplacians of the SLPAs (colors) and of the WSCAs (contours) onto the Niño-3.4 index. A zonally elongated local minimum of the SLPA Laplacian is collocated over the local minimum of the WSCAs in the eastern tropical Pacific. The zonal averages of the meridional plots of these two variables from $135^{\circ}$ to $110^{\circ} \mathrm{W}$ (Fig. 9b) show negative peaks at around $10^{\circ} \mathrm{N}$ in the North Pacific. In the South Pacific, the SLPA Laplacian is negative at around $7^{\circ} \mathrm{S}$, where a negative WSCA is found, although the two peaks are not completely collocated because the WSCA amplitudes show equatorward increases due to the smaller values of the Coriolis parameter near the equator. This correspondence in latitude among the SLPA Laplacians, WSCAs, and SSHAs suggests that the anomalous atmospheric circulations over the eastern Pacific, after being adjusted to the underlying SSTAs, are responsible for the formation of the off-equatorial Rossby waves on either side of the equator that are observed after the mature phases of ENSO events. Figures $9 \mathrm{c}$ and $9 \mathrm{~d}$ and Figs. 9e and $9 \mathrm{f}$ show the regressed anomalies based on only $\partial^{2}$ (SLPA) $/ \partial y^{2}$ and $\partial^{2}$ (SLPA) $/ \partial x^{2}$, respectively. Comparison of the lower panels in Fig. 9 indicates that the meridional gradient of the zonal geostrophic wind anomalies is the major contributor to the total magnitude of the SLPA Laplacian.

\section{Discussion}

\section{a. Comparison with conceptual ENSO models}

As presented in the previous sections, the ENSOrelated off-equatorial Rossby waves in $180^{\circ}-120^{\circ} \mathrm{W}$ on either side of the equator are generated by the ENSOrelated WSCAs over the eastern tropical Pacific in $135^{\circ}-$ $90^{\circ} \mathrm{W}$. This result indicates that these Rossby waves are related to the ENSO models proposed in previous studies (Suarez and Schopf 1988; Picaut et al. 1997). In this subsection, we will discuss how our results are related to the existing ENSO models.

In the delayed-action oscillator model (Suarez and Schopf 1988), the equatorial Kelvin wave and the Rossby waves are linked to each other by air-sea 

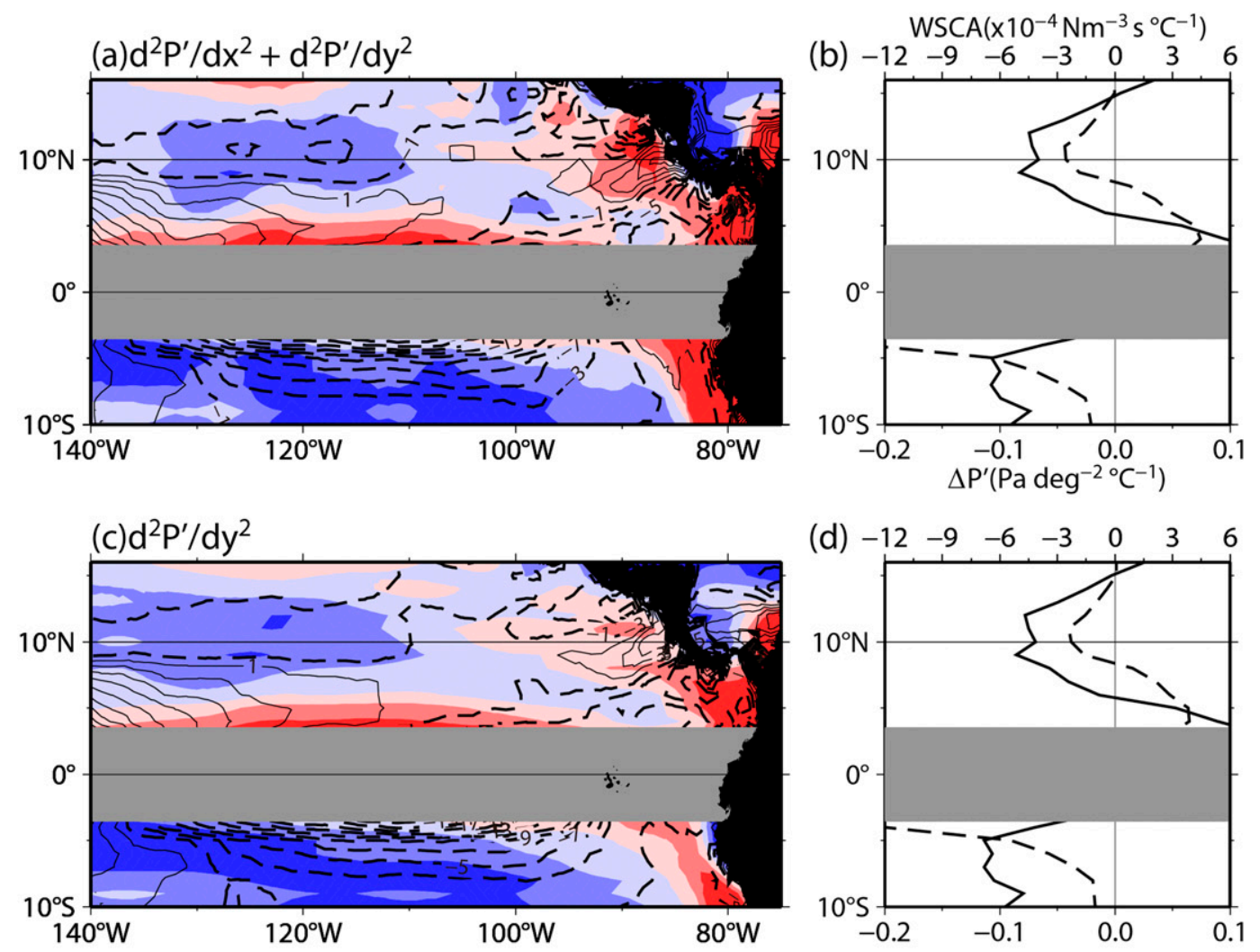

\section{$(e) d^{2} P^{\prime} / d x^{2}$}
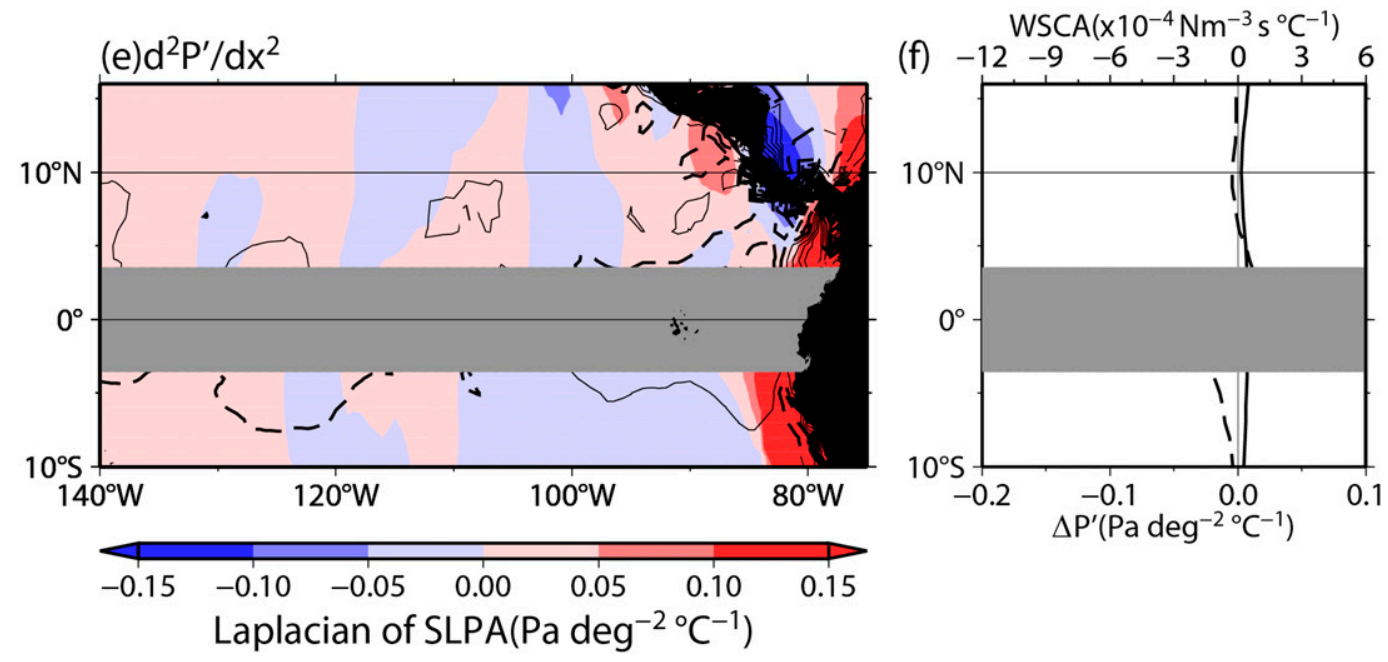

FIG. 9. (a) Regression map of Laplacian of SLPAs (color, $\mathrm{Pa} \mathrm{deg}{ }^{-2}{ }^{\circ} \mathrm{C}^{-1}$ ) and WSCAs (contours, dashed line for negative and solid line for positive with $2.0 \times 10^{-4} \mathrm{~N} \mathrm{~m}^{-3} \mathrm{~s}^{\circ} \mathrm{C}^{-1}$ intervals) onto Niño-3.4 index. Laplacian of SLPAs is smoothed with Gaussian filter with an $e$-folding scale of $3^{\circ} \times 3^{\circ}$. (b) Meridional plots of these two variables zonally averaged over $135^{\circ}-110^{\circ} \mathrm{W}$ (solid line for SLPA and dashed line for WSCA). Figs. 9c and $9 \mathrm{~d}$ and Figs. 9e and 9f show regressed anomalies using only $\partial^{2}(\mathrm{SLPA}) / \partial y^{2}$ and $-\partial\left(\tau^{\prime x} / f\right) / \partial y$ and $\partial^{2}(\mathrm{SLPA}) / \partial x^{2}$ and $\partial\left(\tau^{\prime y} / f\right) / \partial x$, respectively. Equatorial area at $3^{\circ} \mathrm{S}-3^{\circ} \mathrm{N}$ is masked by gray due to small Coriolis parameter.

interaction. Battisti and Hirst (1989) formulated this conceptual delayed oscillator model and argued that this oscillator could account for important aspects of the numerical simulation by Zebiak and Cane (1987). The atmospheric response to the downwelling Kelvin wave, in the delayed-action oscillator model, induces cyclonic WSCAs in the central equatorial Pacific that eventually generate upwelling Rossby waves at $5^{\circ}-7^{\circ} \mathrm{N}$ and $5^{\circ}-7^{\circ} \mathrm{S}$ 
during El Niño events. In contrast, in the eastern tropical Pacific, the present study showed that anticyclonic WSCAs are formed as the atmospheric response to warm Kelvin waves and that this wind forcing generates downwelling Rossby waves in the off-equator regions at $11^{\circ} \mathrm{N}$ and $8^{\circ} \mathrm{S}$ during El Niño events. The amplitudes of the SSHAs are both $2-4 \mathrm{~cm}$ (Fig. 5 of their study and Fig. 5 of the present study), but the polarity of the Rossby waves is different. The polarity of the Rossby waves in the central equatorial Pacific, which is expected in the delayed-action oscillator model, is opposite to that of the observed ones in the off-equatorial regions of the eastern tropical Pacific, as shown in the present study. This means that the upwelling Rossby waves in the delayed-action oscillator model contribute to the termination of the ongoing El Niño event. In contrast, the downwelling Rossby waves that were investigated in the present study could contribute to the preparation of the next El Niño event after arriving in the western tropical Pacific (Hasegawa and Hanawa 2007).

Picaut et al. (1997) proposed the advective-reflective oscillator model. In this conceptual model, the Kelvin wave reflection at the eastern coastal boundary toward the subsequent off-equatorial Rossby wave is one of the key factors that determine the length of an ENSO cycle; the ENSO period in this conceptual model is realistic (3.8 yr on average) when the equatorial Kelvin wave is assumed to completely reflect at the eastern boundary, whereas it is unrealistic (much longer than $3.8 \mathrm{yr}$ ) when the reflection ratio is set to be small. The observational results of the present study show the important role of anomalous wind forcing in the generation of Rossby waves in the off-equatorial belts during the mature phases of ENSO events, although the wave reflection effect is not negligible for some Rossby waves. The polarity of Rossby waves that is expected in the advectivereflective oscillator model is the same as that of Rossby waves in the present study, but the conclusion of the present study is that the main forcing for the Rossby wave generations in 1993-2013 is the ENSO-related wind forcing rather than the Kelvin wave reflection. In contrast, the strong El Niño event occurring in 1997/98 shows the wave reflection at the eastern boundary as expected from the advective-reflective oscillator. Therefore, the present results indicate that the magnitude of wave reflection at the eastern coastal boundary is different depending on the type of ENSO events. This point is also discussed in the next subsection.

The observational evidence shown in the present study indicates that the climate processes related to ENSO include the wind-forced Rossby waves in the offequatorial eastern tropical Pacific in addition to the equatorial Rossby waves that are emphasized in the delayed-action oscillator model and the wave reflection at the eastern boundary emphasized in the advectivereflective oscillator model.

\section{b. Comparison with relevant works}

As explained in the introduction, the presence of the ENSO-related Rossby waves in the eastern tropical Pacific is reported by the previous studies (e.g., Kessler 1990; Hasegawa and Hanawa 2003; White et al. 2003). These off-equatorial Rossby waves in the eastern tropical Pacific are considered as the boundary-driven waves because the wave reflection was indeed captured in the strong 1997/98 El Niño event (Fu and Qiu 2002; Vega et al. 2003; Ramos et al. 2008). The satellite SSHA data currently available for more than $20 \mathrm{yr}$ cover enough ENSO events, including the strong El Niño event in $1997 / 98$ and weak El Niño events in the 2000s (e.g., Larkin and Harrison 2005; Ashok et al. 2007; Yu and Kao 2007; Kug et al. 2009). This enables us to describe not only common features found in all the ENSOrelated Rossby waves but also their diversity.

With this advantage, we found that the ENSO-related Rossby waves are observed at every 10 ENSO events (Fig. 2). Statistical analysis for the observed SSHA field, however, showed that the strong SSHA signal emitted from the coastal boundary, as was seen in the 1997/98 El Niño event, was not found in the other ENSO events. This fact indicates that another mechanism is required to explain the ENSO-related Rossby wave formations. Our numerical experiment using the 1.5-layer reducedgravity model driven by the wind forcing suggests that the anomalous wind stress curl in $135^{\circ}-90^{\circ} \mathrm{W}$ (Fig. 3) can reasonably explain the Rossby wave formation in $180^{\circ}-$ $120^{\circ} \mathrm{W}$ including its polarity as observed (Figs. 2, 4, 5). Further, westward shifts of the SSHA formation areas during the El Niño Modoki events were observed (Figs. 2, 4). An interbasin comparison of the SSHAs indicated that there was no essential difference in formations of the ENSO-related Rossby waves in the North and South Pacific (Figs. 2a,b and Figs. 4a,b).

An importance of anomalous winds in the central to western tropical Pacific on forming/enhancing Rossby waves has been reported by numerous studies (e.g., Kessler 1990; Weisberg and Wang 1997; White et al. 2003; Hasegawa and Hanawa 2007; Hasegawa et al. 2008; Qiu and Chen 2010; Chang et al. 2013). The windinduced Rossby waves in the western tropical Pacific have an impact on the equatorial SSH variability through the western boundary reflection (McGregor et al. 2007, 2008 2009a,b). We additionally suggested that the anomalous winds in the eastern tropical Pacific, specifically in $135^{\circ}-90^{\circ} \mathrm{W}$ (Fig. 3), are also important for the Rossby wave formations in $180^{\circ}-120^{\circ} \mathrm{W}$. 
Perkins and Holbrook (2001) conducted numerical simulations of a 1.5-layer reduced-gravity model forced by WSCAs with various model settings. They examined which of the model settings was appropriate to represent thermocline depth variability (i.e., SSHA) at a wide variety of latitudes of $11^{\circ} \mathrm{N} / \mathrm{S}, 21^{\circ} \mathrm{N} / \mathrm{S}$, and $31^{\circ} \mathrm{N} / \mathrm{S}$ in the western to eastern Pacific, simulated in an eddypermitting ocean model developed by Semtner and Chervin (1992). Their results, especially those in the eastern tropical parts of $11^{\circ} \mathrm{N} / \mathrm{S}$ (Figs. $6 \mathrm{f}$ and $6 \mathrm{c}$ of their study), can be compared with Figs. $5 \mathrm{a}$ and $5 \mathrm{~b}$ of the present study. The longitudinal distributions of the correlation coefficients, calculated using the simulations of the eddy-permitting ocean model and the 1.5-layer model, showed westward increases along $11^{\circ} \mathrm{N}$ and $11^{\circ} \mathrm{S}$ (Figs. 6f and $6 \mathrm{c}$ of their study), as depicted in Fig. 5a $\left(11^{\circ} \mathrm{N}\right)$ and Fig. $5 \mathrm{~b}\left(8^{\circ} \mathrm{S}\right)$. The ranges of the correlation coefficients in Perkins and Holbrook (2001) $(+0.2$ to +0.7 at $11^{\circ} \mathrm{N}$ and -0.2 to +0.7 at $11^{\circ} \mathrm{S}$ ) and the present study $\left(+0.0\right.$ to +0.8 at $11^{\circ} \mathrm{N}$ and +0.1 to +0.7 at $8^{\circ} \mathrm{S}$ ) are comparable. As explained in section $3 \mathrm{~b}$, the high correlation coefficients in $180^{\circ}-120^{\circ} \mathrm{W}$ reflect the importance of the winds on the Rossby wave formations. Thus, we further examined spatial patterns of anomalous wind vectors and WSCAs during the mature phase of ENSO events as described in the next paragraph.

We found that the wind forcing anomalies are the result of the lower atmospheric response to the underlying SST warming of El Niño. Although the magnitude of the anomalous easterlies itself is not stronger than the anomalous westerlies in the western Pacific, spatial differential components of the anomalous surface winds were statistically significant in the eastern tropical Pacific, contributing to the anticyclonic WSCA formations in the same regions. While the presence of the anticyclonic WSCA in the North Pacific is reported by Abe et al. (2014), the present study additionally showed that this structure is found in the South Pacific as well. These anticyclonic WSCAs in the eastern tropical North and South Pacific during the mature phase of El Niño (cyclonic WSCAs during mature phase of La Niña) are important for the downwelling Rossby wave formations (upwelling Rossby wave formations).

\section{Summary}

The formations of the ENSO-related off-equatorial Rossby waves in the eastern tropical North and South Pacific were examined using satellite SSHA data and atmospheric variables in the reanalysis dataset during the period of 1993-2013. The downwelling Rossby waves (upwelling Rossby waves) were formed and propagated along off-equatorial latitude bands in the eastern tropical North and South Pacific after the mature phase of El Niño (La Niña). These off-equatorial Rossby waves had been considered a result of the reflection of the equatorial Kelvin wave on the eastern coastal boundary. The present study revealed that the ENSO-related Rossby waves $180^{\circ}-120^{\circ} \mathrm{W}$ can also be excited by anomalous wind forcing in the eastern tropical Pacific in $135^{\circ}-90^{\circ} \mathrm{W}$ during the mature phase of ENSO events. Off-equatorial zonal belts of anticyclonic (cyclonic) WSCAs found in $8^{\circ}-14^{\circ} \mathrm{N}$ and $3^{\circ}-15^{\circ} \mathrm{S}$ in the eastern tropical North and South during mature phases of El Niño (La Niña) events can explain downwellng Rossby wave formations (upwelling Rossby wave formations) on either side of the equator.

According to analyses of satellite SSHA data in 1993 2013, positive (negative) SSHAs were distinct at $11^{\circ} \mathrm{N}$ and $8^{\circ} \mathrm{S}$ for every El Niño event (every La Niña event). However, except for the strong El Niño event in 1997/98, the starting longitudes of the ENSO-related SSHA propagations were distant from the eastern coastal boundary. Especially, this propagation feature was evident in the 2000s that is characterized by frequent occurrence of El Niño Modoki events. A numerical experiment based on a simple dynamic model driven only by anticyclonic (cyclonic) wind stress anomalies well reproduced the observed downwelling (upwelling) Rossby waves on either side of the equator without consideration of the wave emission from the eastern boundary. The experimental results strongly suggest that the surface wind anomalies associated with ENSO events are necessary for the formation of the ENSOrelated off-equatorial Rossby waves.

Because of the hydrostatic response of the lower atmosphere to the underlying warm (cool) SSTAs during mature phases of El Niño (La Niña) events, equatorially symmetric patterns of negative (positive) SLPAs were formed over the eastern tropical Pacific. This study's analysis of surface wind anomaly fields showed that the meridional gradient of the zonal component of geostrophic surface wind velocities contribute significantly to the formation of WSCA zonal belts on either side of the equator. This finding indicates that spatial SLPA distributions are a key in describing the formation of offequatorial Rossby waves on either side of the equator after the mature phases of ENSO events.

Acknowledgments. We thank the editor (Dr. Gregory Foltz) and three anonymous reviewers who provided valuable comments that contributed to the improvement of this manuscript. The satellite altimeter data were provided by AVISO, the surface wind and SLP data were provided by ECMWF, the Niño-3.4 index were provided by NOAA, and the SST data were provided 
by the Met Office Hadley Centre. The authors thank all of the data providers. The authors' appreciations go to Enago (www.enago.jp) for the English language review. This study was supported partially by Grand-In-Aid for Scientific Research by the Ministry of Education, Culture, Sports, Science, and Technology of Japan (15K05279, 26241003, and 16H04046) and the Sumitomo Foundation (153168).

\section{REFERENCES}

Abe, H., Y. Tanimoto, T. Hasegawa, N. Ebuchi, and K. Hanawa, 2014: Oceanic Rossby waves induced by the meridional shift of the ITCZ in association with ENSO events. J. Oceanogr., 70, 165-174, doi:10.1007/s10872-014-0220-1.

Ashok, K., S. K. Behera, S. A. Rao, H. Weng, and T. Yamagata, 2007: El Niño Modoki and its possible teleconnection. J. Geophys. Res., 112, C11007, doi:10.1029/2006JC003798.

Battisti, D. S., and A. C. Hirst, 1989: Interannual variability in the tropical atmosphere-ocean system: Influences of the basic state, ocean geometry and nonlinearity. J. Atmos. Sci., 46, 1687-1712, doi:10.1175/1520-0469(1989)046<1687:IVIATA > 2.0.CO;2.

Blanco, J. L., M. E. Carr, A. C. Thomas, and P. T. Strub, 2002: Hydrographic conditions off northern Chile during the 19961998 La Niña and El Niño events. J. Geophys. Res., 107, 3-1-3-19, doi:10.1029/2001JC001002.

Capotondi, A., M. A. Alexander, and C. Deser, 2003: Why are there Rossby wave maxima in the Pacific at $10^{\circ} \mathrm{S}$ and $13^{\circ} \mathrm{N}$ ? J. Phys. Oceanogr., 33, 1549-1563, doi:10.1175/2407.1.

Chang, Y.-T., L. Du, S.-W. Zhang, and P.-F. Huang, 2013: Sea level variations in the tropical Pacific Ocean during two types of recent El Niño events. Global Planet. Change, 108, 119-127, doi:10.1016/j.gloplacha.2013.06.001.

Chelton, D. B., and M. G. Schlax, 1996: Global observations of oceanic Rossby waves. Science, 272, 234-238, doi:10.1126/ science.272.5259.234.

Clarke, A. J., 2008: An Introduction to the Dynamics of El Niño and the Southern Oscillation. Elsevier, 324 pp.

—, and C. Shi, 1991: Critical frequencies at ocean boundaries. J. Geophys. Res., 96, 10731-10 738, doi:10.1029/91JC00933.

__ , and S. Van Gorder, 1994: On ENSO coastal currents and sea levels. J. Phys. Oceanogr., 24, 661-680, doi:10.1175/ 1520-0485(1994)024<0661:OECCAS > 2.0.CO;2.

Cummins, P. F., and G. S. E. Lagerloef, 2004: Wind-driven interannual variability over the northeast Pacific Ocean. DeepSea Res. I, 51, 2105-2121, doi:10.1016/j.dsr.2004.08.004.

Dee, D. P., and Coauthors, 2011: The ERA-Interim reanalysis: Configuration and performance of the data assimilation system. Quart. J. Roy. Meteor. Soc., 137, 553-597, doi:10.1002/ qj. 828 .

Fu, L. L., and B. Qiu, 2002: Low-frequency variability of the North Pacific Ocean: The roles of boundary- and wind-driven baroclinic Rossby waves. J. Geophys. Res., 107, 3220, doi:10.1029/ 2001JC001131.

Giunipero, E. M., and A. J. Clarke, 2013: Estimation of the effect of eddies on coastal El Niño flows using along-track satellite altimeter data. J. Phys. Oceanogr., 43, 1209-1224, doi:10.1175/ JPO-D-12-0109.1.

Hasegawa, T., and K. Hanawa, 2003: Heat content variability related to ENSO events in the Pacific. J. Phys. Oceanogr., 33, 407-420 doi:10.1175/1520-0485(2003)033<0407:HCVRTE>2.0.CO;2.
— , and - 2007: Upper ocean heat content and atmospheric anomaly fields in the off-equatorial North Pacific related to ENSO. J. Oceanogr., 63, 561-572, doi:10.1007/s10872-007-0050-5.

_ , T. Yasuda, and K. Hanawa, 2007: Generation mechanism of quasidecadal variability of upper ocean heat content in the equatorial Pacific Ocean. J. Geophys. Res., 112, C08012, doi:10.1029/2006JC003755.

_, K. Hanawa, Y. M. Tourre, and W. B. White, 2008: Absence of propagating upper ocean heat content anomalies in the eastern tropical South Pacific after ENSO events. Geophys. Res. Lett., 35, L09607, doi:10.1029/2007GL033065.

Holbrook, N. J., and N. L. Bindoff, 1999: Seasonal temperature variability in the upper southwest Pacific Ocean. J. Phys. Oceanogr., 29, 366-381, doi:10.1175/1520-0485(1999)029<0366: STVITU $>2.0 . \mathrm{CO} ; 2$.

Kalnay, E., and Coauthors, 1996: The NCEP/NCAR 40-Year Reanalysis Project. Bull. Amer. Meteor. Soc., 77, 437-471, doi:10.1175/1520-0477(1996)077<0437:TNYRP>2.0.CO;2.

Kaplan, A., Y. Kushnir, M. A. Cane, and M. B. Blumenthal, 1997: Reduced space optimal analysis for historical data sets: 136 years of Atlantic sea surface temperatures. J. Geophys. Res., 102, 27 835-27 860, doi:10.1029/97JC01734.

Kessler, W. S., 1990: Observations of long Rossby waves in the northern tropical Pacific. J. Geophys. Res., 95, 5183-5217, doi:10.1029/JC095iC04p05183.

Kug, J.-S., F.-F. Jin, and S.-I. An, 2009: Two types of El Niño events: Cold tongue El Niño and warm pool El Niño. J. Climate, 22, 1499-1515, doi:10.1175/2008JCLI2624.1.

Larkin, N. K., and D. E. Harrison, 2005: On the definition of El Niño and associated seasonal average U.S. weather anomalies. Geophys. Res. Lett., 32, L13705, doi:10.1029/2005GL022738.

McGregor, S., N. J. Holbrook, and S. B. Power, 2007: Interdecadal sea surface temperature variability in the equatorial Pacific Ocean. Part I: The role of off-equatorial wind stresses and oceanic Rossby waves. J. Climate, 20, 2643-2658, doi:10.1175/ JCLI4145.1.

,-- , and -2008 : Interdecadal sea surface temperature variability in the equatorial Pacific Ocean. Part II: The role of equatorial/off-equatorial wind stresses in a hybrid coupled model. J. Climate, 21, 4242-4251, doi:10.1175/2008JCLI2057.1.

_ _ - and - 2009a: The response of a stochastically forced ENSO model to observed off-equatorial wind-stress forcing. J. Climate, 22, 2512-2528, doi:10.1175/2008JCLI2387.1.

_ A. Sen Gupta, N. J. Holbrook, and S. B. Power, 2009b: The modulation of ENSO variability in CCSM3 by extratropical Rossby waves. J. Climate, 22, 5839-5853, doi:10.1175/ 2009JCLI2922.1.

McPhaden, M. J., and X. Yu, 1999: Equatorial waves and the 199798 El Niño. Geophys. Res. Lett., 26, 2961-2964, doi:10.1029/ 1999GL004901.

McWilliams, J. C., 2006: Fundamentals of Geophysical Fluid Dynamics. Cambridge University Press, 249 pp.

Meyers, G., 1979: On the annual Rossby wave in the tropical North Pacific Ocean. J. Phys. Oceanogr., 9, 663-674, doi:10.1175/ 1520-0485(1979)009<0663:OTARWI > 2.0.CO;2.

Perkins, M. L., and N. J. Holbrook, 2001: Can Pacific Ocean thermocline depth anomalies be simulated by a simple linear vorticity model? J. Phys. Oceanogr., 31, 1786-1806, doi:10.1175/ 1520-0485(2001)031<1786:CPOTDA > 2.0.CO;2.

Picaut, J., C. Menkes, J. P. Boulanger, and Y. du Penhoat, 1993: Dissipation in a Pacific equatorial long wave model. TOGA Notes, 10,11-15. [Available online at http://horizon.documentation.ird. fr/exl-doc/pleins_textes/pleins_textes_6/b_fdi_35-36/39887.pdf.] 
_ - F. Masia, and Y. du Penhoat, 1997: An advective-reflective conceptual model for the oscillatory nature of the ENSO. Science, 277, 663-666, doi:10.1126/science.277.5326.663.

Pizarro, O., G. Shaffer, B. Dewitte, and M. Ramos, 2002: Dynamics of seasonal and interannual variability of the Peru-Chile Undercurrent. Geophys. Res. Lett., 29, 22-1-22-4, doi:10.1029/2002GL014790.

Qiu, B., and S. Chen, 2010: Interannual-to-decadal variability in the bifurcation of the North Equatorial Current off the Philippines. J. Phys. Oceanogr., 40, 2525-2538, doi:10.1175/ 2010JPO4462.1.

Ramos, M., B. Dewitte, O. Pizarro, and G. Garric, 2008: Vertical propagation of the extratropical Rossby wave during the 1997-1998 El Niño off the west coast of South America in a medium-resolution OGCM simulation. J. Geophys. Res., 113, C08041, doi:10.1029/2007JC004681.

Rayner, N. A., D. E. Parker, E. B. Horton, C. K. Folland, L. V. Alexander, D. P. Rowell, E. C. Kent, and A. Kaplan, 2003: Global analyses of sea surface temperature, sea ice, and night marine air temperature since the late nineteenth century. J. Geophys. Res., 108, 4407, doi:10.1029/2002JD002670.

Schopf, P. S., and M. J. Suarez, 1988: Vacillations in a coupled ocean-atmosphere model. J. Atmos. Sci., 45, 549-566, doi:10.1175/1520-0469(1988)045<0549:VIACOM >2.0.CO;2.

Semtner, A. J., and R. M. Chervin, 1992: Ocean general circulation from a global eddy-resolving model. J. Geophys. Res., 97, 5493-5550, doi:10.1029/92JC00095.

Simmons, A. J., K. M. Willett, P. D. Jones, P. W. Thorne, and D. P. Dee, 2010: Low- frequency variations in surface atmospheric humidity, temperature, and precipitation: Inferences from reanalyses and monthly gridded observational data sets. J. Geophys. Res., 115, D01110, doi:10.1029/2009JD012442.

Singh, A., T. Delcroix, and S. Cravatte, 2011: Contrasting the flavors of El Niño-Southern Oscillation using sea surface salinity observations. J. Geophys. Res., 116, C06016, doi:10.1029/2010JC00686.

Strub, P. T., and C. James, 2002: Altimeter-derived surface circulation in the large-scale NE Pacific Gyres. Part 2: 1997-1998 El Niño anomalies. Prog. Oceanogr., 53, 185-214, doi:10.1016/ S0079-6611(02)00030-7.

Suarez, M. J., and P. S. Schopf, 1988: A delayed action oscillator for ENSO. J. Atmos. Sci., 45, 3283-3287, doi:10.1175/ 1520-0469(1988)045<3283:ADAOFE > 2.0.CO;2.

Vega, A., Y. du-Penhoat, B. Dewitte, and O. Pizarro, 2003: Equatorial forcing of interannual Rossby waves in the eastern South Pacific. Geophys. Res. Lett., 30, 1197, doi:10.1029/2002GL015886.

Weisberg, R. H., and C. Wang, 1997: A western Pacific oscillator paradigm for the El Niño-Southern Oscillation. Geophys. Res. Lett., 24, 779-782, doi:10.1029/97GL00689.

White, W. B., Y. M. Tourre, M. Barlow, and M. Dettinger, 2003: A delayed action oscillator shared by biennial, interannual, and decadal signals in the Pacific basin. J. Geophys. Res., 108, 3070, doi:10.1029/2002JC001490.

Yu, J.-Y., and H.-Y. Kao, 2007: Decadal changes of ENSO persistence barrier in SST and ocean heat content indices: 1958-2001. J. Geophys. Res., 112, D13106, doi:10.1029/2006JD007715.

Zebiak, S. E., and M. A. Cane, 1987: A model El Niño-Southern Oscillation. Mon. Wea. Rev., 115, 2262-2278, doi:10.1175/ 1520-0493(1987)115<2262:AMENO>2.0.CO;2. 